\title{
DEVELOPING CREATIVITY ABILITIES AND ATTITUDE TOWARD DISTANCE E-LEARNING IN (FASHION DESIGN-2) COURSE FOR UNIVERSITY OF NIZWA' STUDENTS AT THE BEGINNING OF PANDEMIC 2020
}

\author{
Rehab Ragab Mahmoud Hassaan
}

Prof. Dr. University of Nizwa, OMAN. Helwan University, Egypt, rehab.ragab@unizwa.edu.om
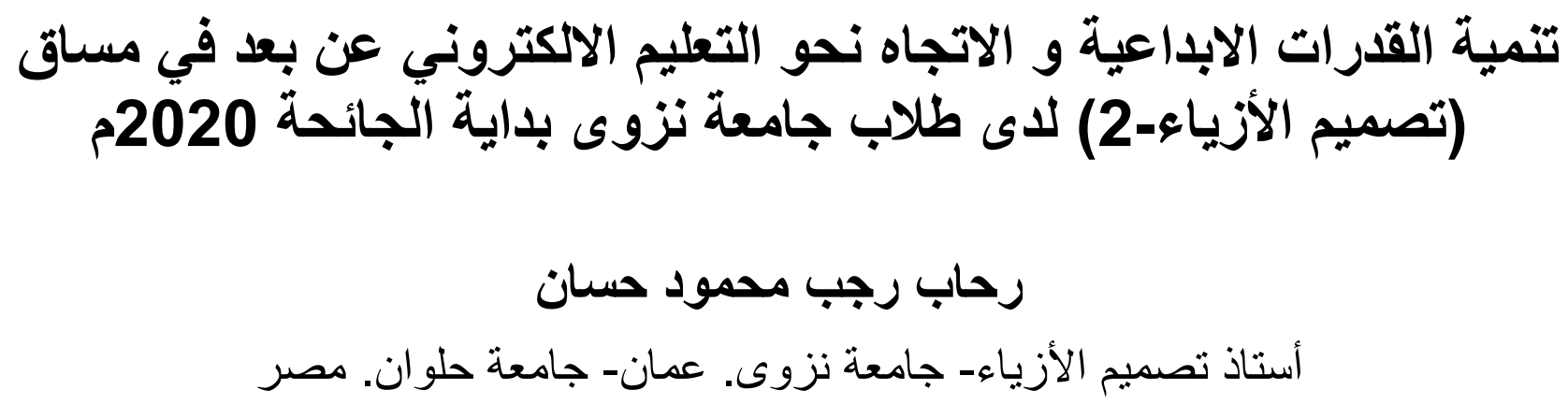

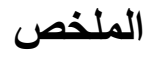

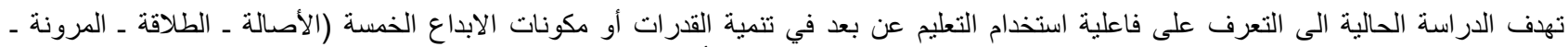

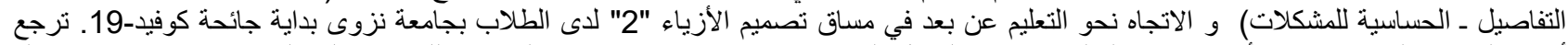

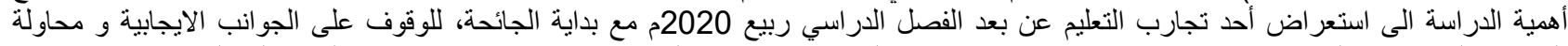

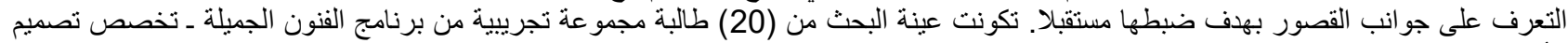

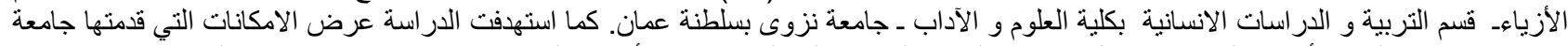

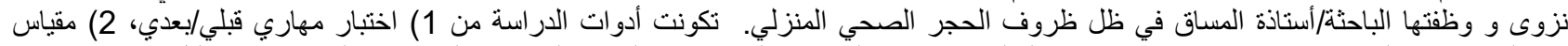

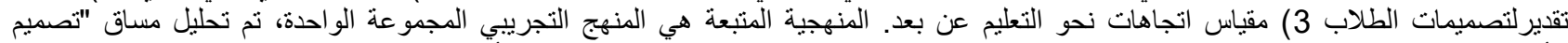

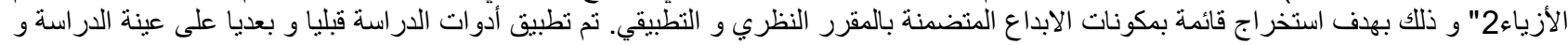

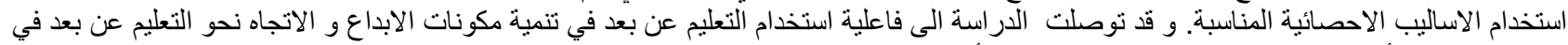

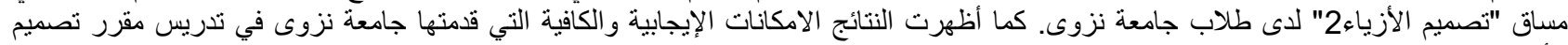
الأزياء بالاعتماد على نظم ادارة التعلم، وتم عرض بعض نعض مشكلات التدريس في متن الدراسة.

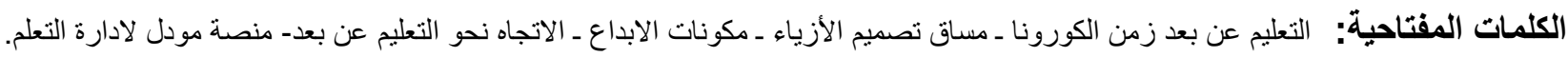

\section{Abstract}

The Objective of the current study is to investigate effectiveness of using distance e-learning in developing creativity abilities and attitude toward distance e-learning in Fashion Design (2) course for Nizwa University students. The significance of the study represents in reviewing one of the experiences of distance e-learning at the beginning of pandemic, to find out the positive aspects and try to identify the shortcomings with a view to controlling them in the future. The study sample consisted of (20) students specialized into one experimental group from Nizwa University-Sultanate of Oman- College of Arts and Sciences- Department of Education and Humanities Culture- Fine Arts Program- Fashion Design Major. The study also aims to show 
the capabilities provided by the University of Nizwa which aided in teaching process in conditions of home quarantine. Study instruments include 1-skills achievements test, 2-Students' designs rating scale, 3-scale of students' attitude toward distance learning. The author followed the one group experimental approach methodology. The content of Fashion Design (2) course was analyzed to determine the five creativity dimensions/abilities included in practical and theoretical frameworks (fluency- flexibility- originalityelaboration- sensitivity). The instruments of current study were applied using a pre-post design on the study sample and appropriate statistical procedures were used. The results of the study indicated the effectiveness of using distance e-learning in developing creativity dimensions and attitude toward distance learning in Fashion Design "2" course for Nizwa University students of the experimental group at favor of post-test. The results also showed positive and sufficient capabilities provided by the University of Nizwa in teaching the fashion design course depending on Eduwave and Moodle management learning systems and finding out some teaching problems addressed in the body of the study.

Keywords :Distance e-learning in covid-19 -Fashion Design course- Creativity dimensions- Attitude toward distance learning- Moodle Management Learning System

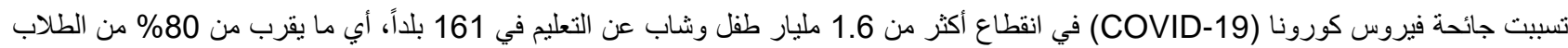

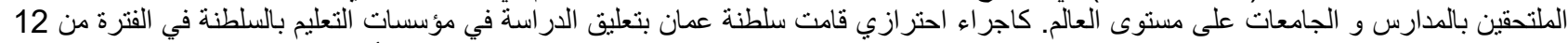
مارس حتى 12 ابريل 2020مئ 2020، من بعدها اقرت التوجه الى التعليم عن بعد حتى نهاية الفصل الدراسي، وافق ذللك الأسبوع الثامن من الدراسة في الفصل الثاني/الربيع 2020.

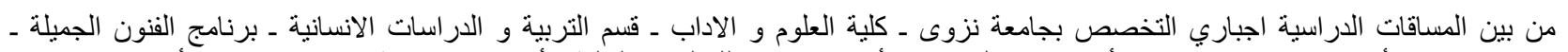

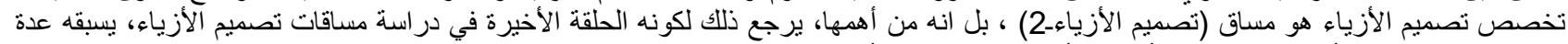

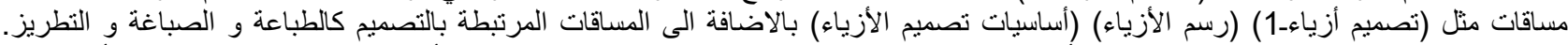

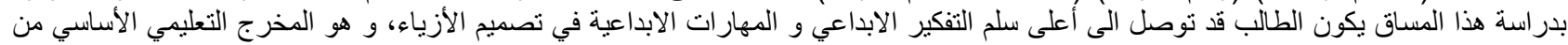

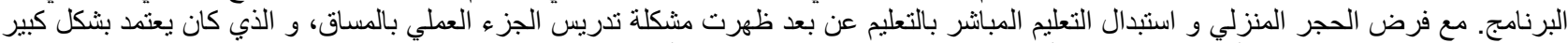

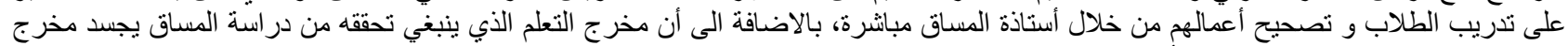

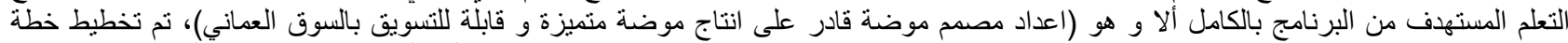

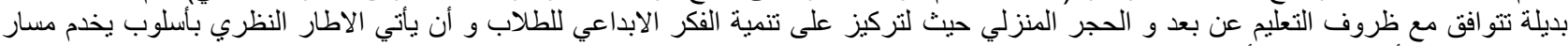

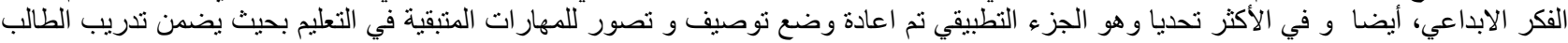

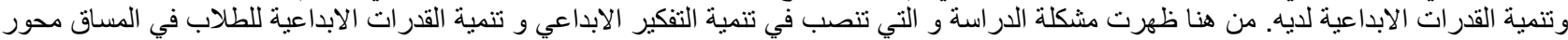

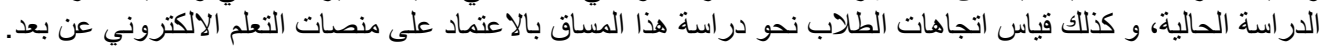

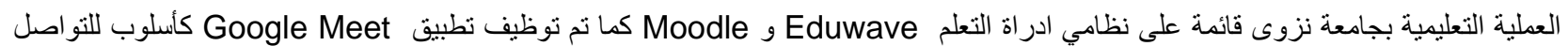

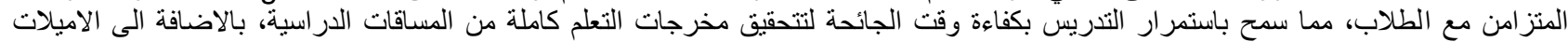

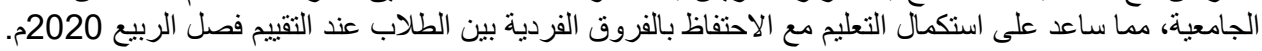

2. التساؤلات

$$
\begin{aligned}
& \text { 1ـ ما امكانية التوصل الى خارطة استرشادية لتعزيز مسار التفكير الابداعي لدى دارسي تصميم الأزياء بجامعة نزوى ـ برنامج الفنون الجميلة ـ ـ } \\
& \text { تخصص تصميم الأزياء؟ ماءن التون } \\
& \text { 2ـ ما امكانية توظيف الخارطة الاسترشادية في تعزيز القدر ات الابداعية لدى دارسي تصميم الأزياء بجامعة نزوى ـ برنامج الفنون الجميلة ـ تخصص } \\
& \text { تصميم الأزياء؟ } \\
& \text { 3ـ ما فاعلية استخدام التعليم عن بعد في مساق "تصميم الأزياء2" في تتمية الاتجاه نحو التعليم عن بعد لدى طلاب جامعة نزوى؟ } \\
& \text { 3. } \\
& \text { تهدف الدر اسة الحالية الى: } \\
& \text { 1ـ الكثف عن مهار ات التفكير الابداعي و تحديد الخطوات الرئيسية بالعملية التصميمبة التي تعزز الابداع لدى دارسي تصميم الأزياء. } \\
& \text { 2- توظيف اسلوب التعليم عن بعد في تعزيز مكونات الابداع في مساق "تصميم الأزياء-2" لدى طلاب جامعة نزوى ـ تخصص الفنون الجميلة ـ تصميم } \\
& \text { الأزياء. } \\
& \text { 3ـ نوظيف التعليم عن بعد في تنمية الاتجاه نحو التعليم عن بعد في مقرر "تصميم الأزياء-2" لاى طلاب جامعة نزوى ـ تخصص الفنون الجميلة ـ تصميم } \\
& \text { الأزياء. } \\
& \text { 4ـ التعريف بنظم ادارة التعلم المستخدمة في التعليم عن بعد بجامعة نزوى و دور ها بالمشاركة مع تطبيقات التو اصل المتز امن. }
\end{aligned}
$$


ترجع أهمية الدراسة الى:

1ـ التوصل الى ملخص أو خارطة استرشادية بمثابة دليل للأستاذ لتعزيز مكونات الابداع لدى دارسي تصميم الأزياء من خلال اسلوب التعليم الالكتروني عن بعد.

2ـ تعد الدر اسة نموذجا مطروحا لتدريس أحد مساقات الفنون العملية في ظل الأزمة المباغتة بداية جائحة كوفيد-19 و اللجوء لأسلوب التعليم عن بعد. 3ـ تقدم الدر اسة مقياس تقدير مهاري و مقياس اتجاهات نحو التعليم عن بعد في مساق "تصميم الأزياء-2" التطبيقي يمكن الافادة منه في دراسات أخرى. 4ـ الافادة من تجارب الجامعات المختلفة في تخطي الأزمة المباغتة لعملية التعليم زمن كوفيد-19 حيث استكمال سير العملية التعليمية بما يضمن حصول

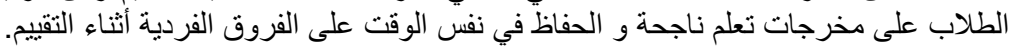

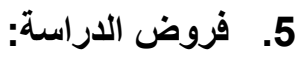

1- يمكن تتمية القدر ات الابداعية في مساق "تصميم الأزياء-2" لدى طلاب جامعة نزوى مع بداية جائحة كورونا و ظروف الحجر المنزلي المباغتة. 2- يمكن تتمية الاتجاه الايجابي للطلاب نحو در اسة مساق "تصميم الأزياء-2" عن بعد من خلال نظم ادارة التعلم و تطبيق التواصل المتز امن زمن جائحة كورونا.

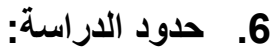

اقتصرت الدراسة الحالية على: ـ طلاب جامعة نزوى ـ كلية العلوم و الآداب ـ قنم التربية و الدر اسات الانسانية ـ تخصص الفنون الجميلة ـ برنامج تصميم الأزياء. ـ الفصل الثاني ـ وقت جائحة كوفيد-19 المباغتة أي النصف الثاني من الفصل الدراسي الثاني/الربيع 2020م. ـ استخدام نظامين لادارة التعلم هما: المنظومة التعليمية Eduwave، و برنامج الـ Moodle، بالاضافة الى أحد تطبيقات التواصل المتزامن و هو تطبيق

Google Meet ـ تحليل القدرات الابداعية في مساق تصميم الأزياء و وضع والقع خارطة لتسلسل التفكير الابداعي في التصميم و تنمية المهارات الابداعية. القدرات الابداعية

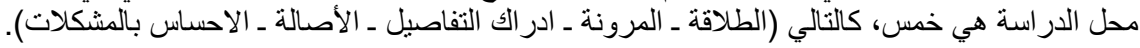
ـ قياس الاتجاه نحو التعليم عن بعد في مساق تصميم الأزياء-2. 7. تتبع الدر اسة المنهج الوصفي في اعداد الاطلار النظري و أدوات الدراسة و تحليل النتائج. و المنهج شبه التجريبي في التجربة المبدانية للار اسة. 8.

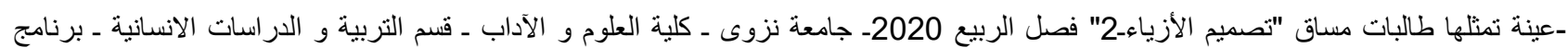

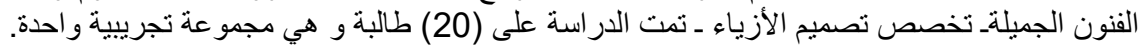
9. مأدوات الاراسة:

تمت اعادة تنظيم توصيف مساق "تصميم الأزياء-2" بعد الجائحة و التوجه للتعليم عن بعد بحيث يشتمل (5) وحلثة وحدات تعليمية مقسمة الى (10)

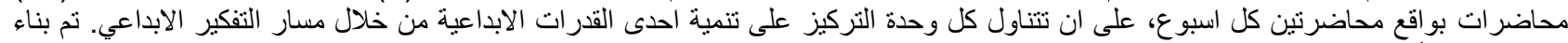

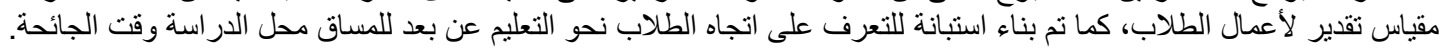
اعداد استبانة الاتجاه نحو التعليم عن بعد و التحقق من الصدق و الثبات:

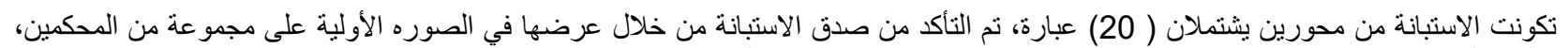

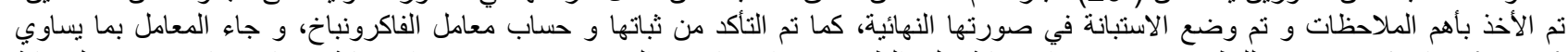

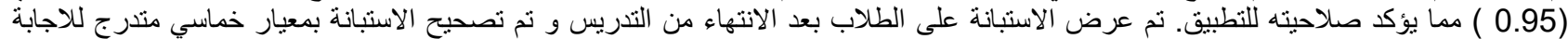

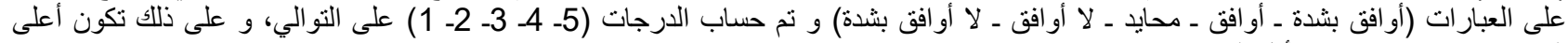

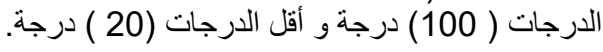
اعداد مقياس تقدير لتقييم أعمال الطلاب التطبيقية بهدف قياس تتمية القدر ات الابداعية.

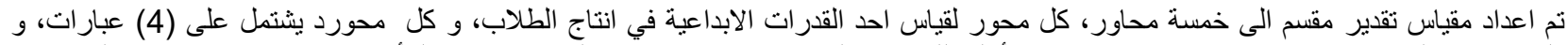

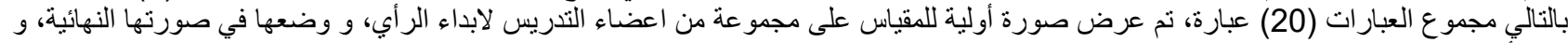

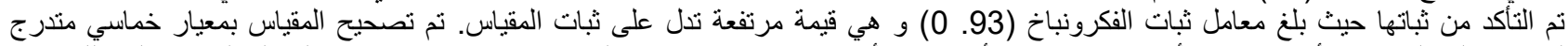

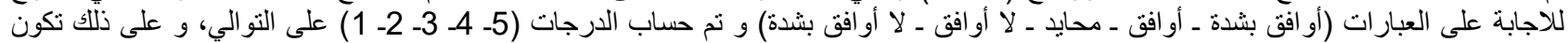

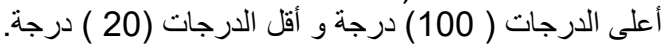

10. 10 مصطلحات الاراسة:

1-10- التعليز:Learning 


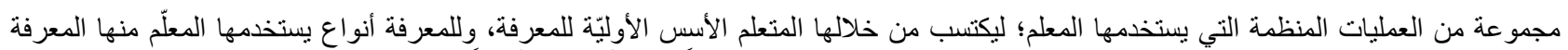

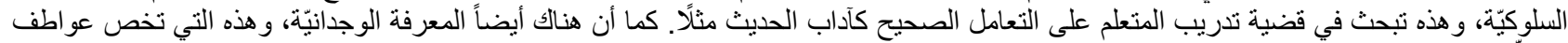

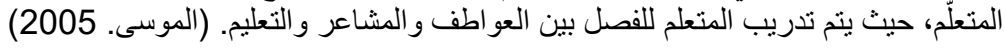

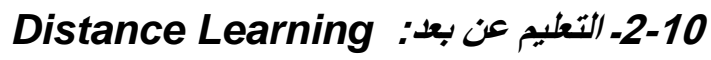

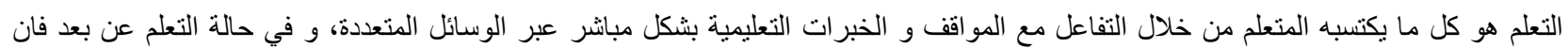

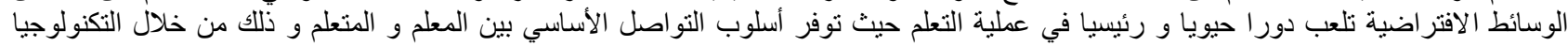
الحديثة التي تسهل اكتساب و تعزيز البنى الادر اكية و المهارية و الوجدانية.

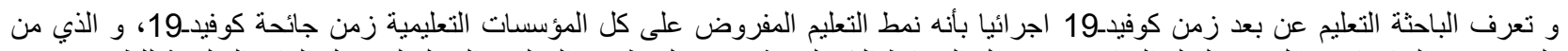

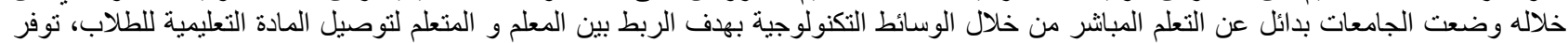

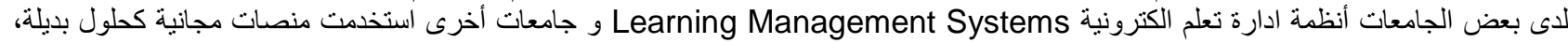

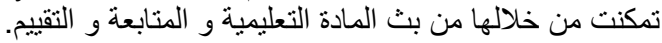

Attitude 3-10 الاتجاه: 3ن

يعرف الاتجاه بأنه: ميل نفسي بدرجة من درجات التفضيل أو عدمه، و يشير تقييم الاتجاهات بالاستجابات التفصيلية سواء كانت ادر اكية أو سلوكية أو وجدانية. (نشواني. 1985)

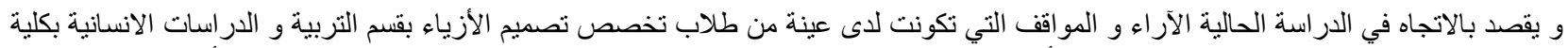

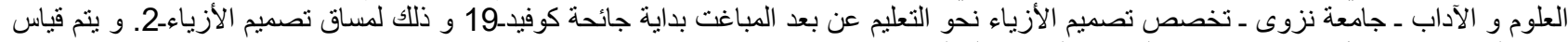

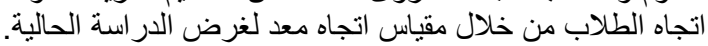

10- 4- كوفبيا- 19: COVID-19

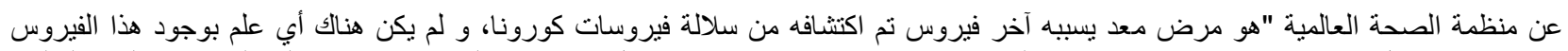

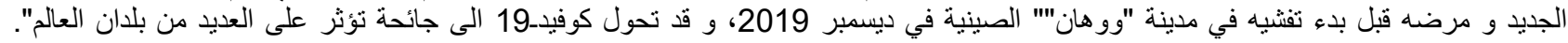

(World Health Organization)

\section{Creative Thinking التفكير الابد/عي: -10-10}

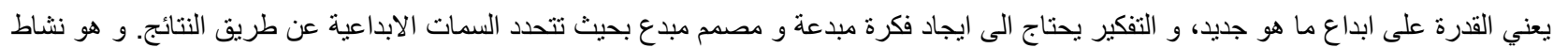

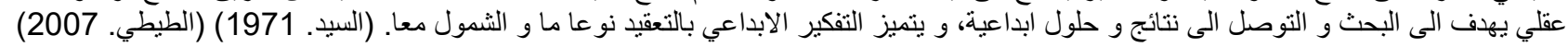

\section{6-10-- مكونات الابداع: Creativity Dimensions}

يشير Perkins إلى أن القدرات الإبداعية: هي مجموعة من القدرات تؤدي إلى إنتاج يتصف بالجدة والأصالة، إضافة إلى عدد من القدرات (قطامي.

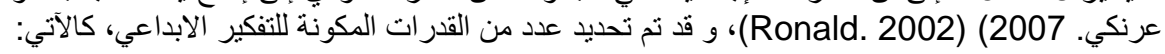

ـ الطلاقة مئة : Fluency هي القدرة على انتاج أكبر عدد ممكن من الأفكار الابداعية، و تقاس هذه القدرة بحساب عدد الأفكار التي يقدمها الفرد عن موضوع معين في وحدة زمنية ثابتة مقارنة مع آداء الأقران.

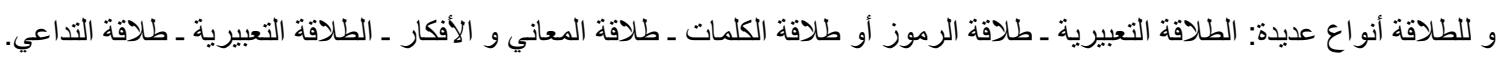

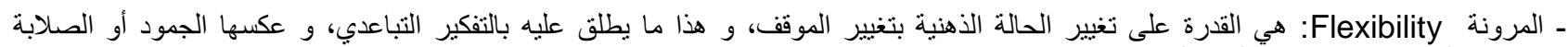
Rigidity

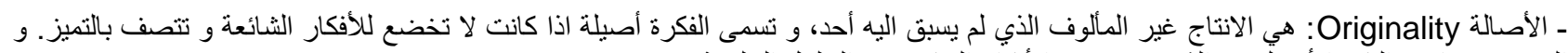

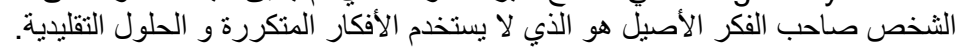

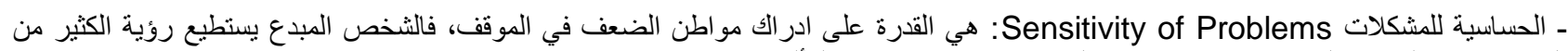
المشكلات في الموقف الواحد، فهو يعي نواحي النقص بسبب نظرته غير المألوفة.

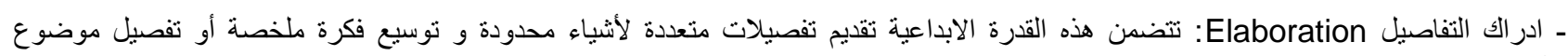
غامض.

$$
\text { 11. أولا: المحور الأول: الاراسات السابقة و التجارب المرتبطة: }
$$

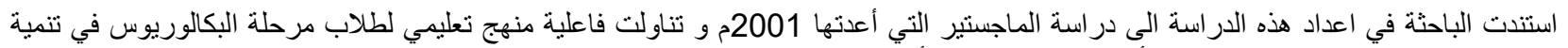

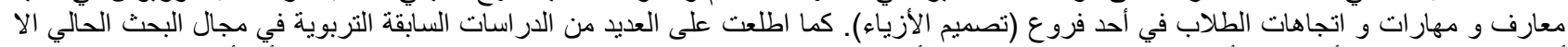

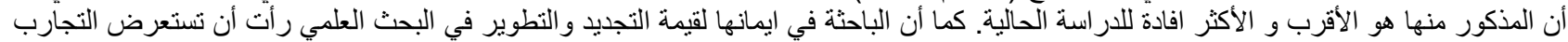

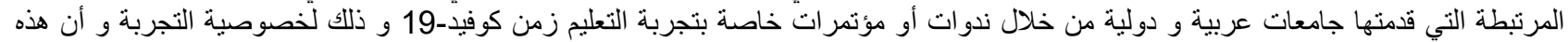

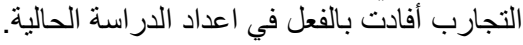

1-11- الدراسات السابقة:

ـ دراسة فؤاد اياد خصاونة: 2015- بعنوان "عملية التفكير الابداعي في التصميم" 


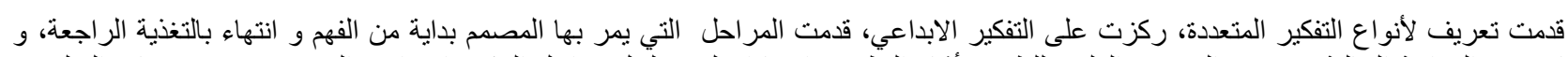

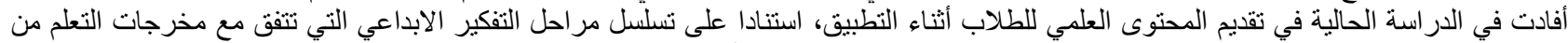

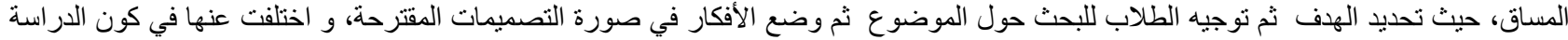

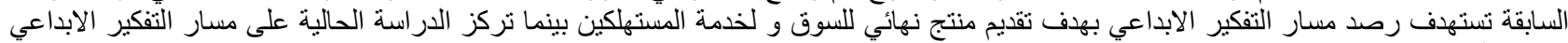

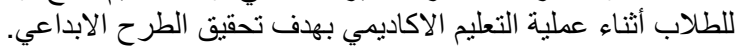

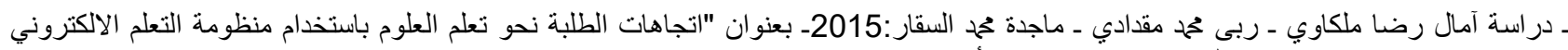
(Eduwave)

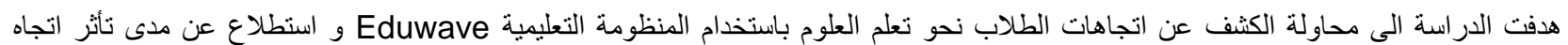

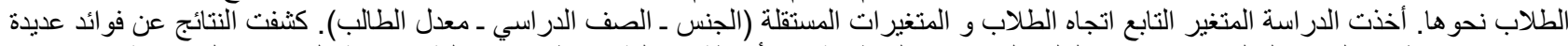

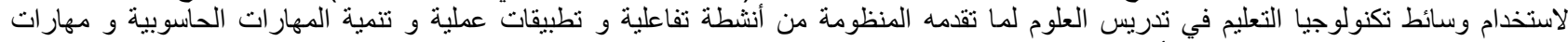

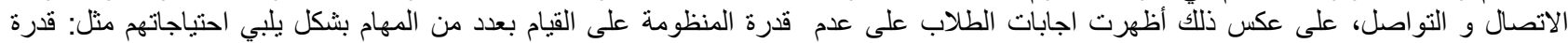

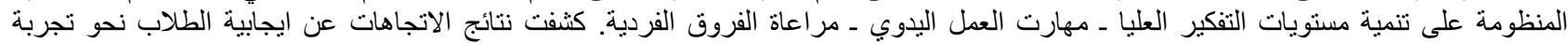

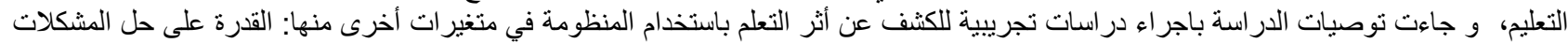

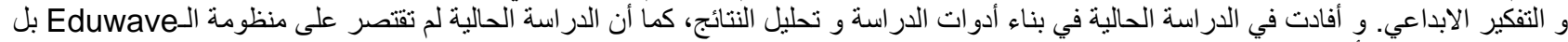

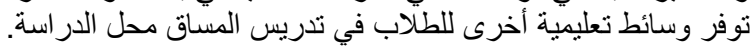

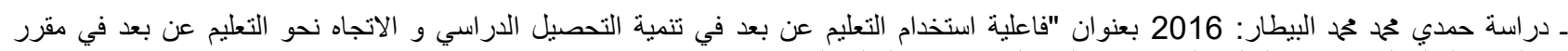
تكنولوجيا التعليم لاى طلاب الدبلوم العامة نظام العام الواحد شعبة التعليم الصناعي".

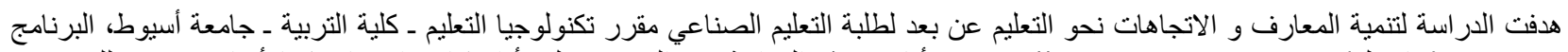

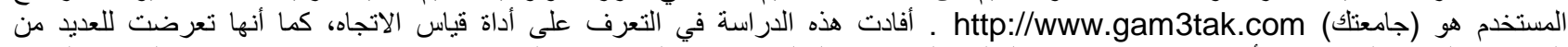

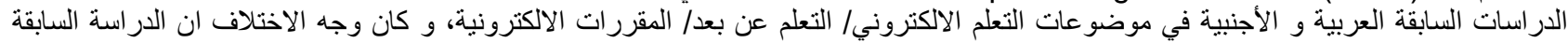

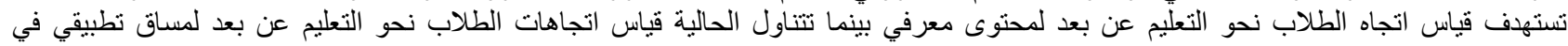

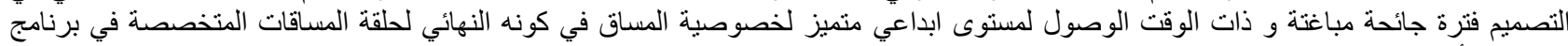

"تصميم الأزياء" بالجامعة.

ـ دراسة ميسم فوزي مطير العزام: 2017 بعنوان "ضمان الجودة النو عية في التعلم الدفتوح و التعلم عن بعد".

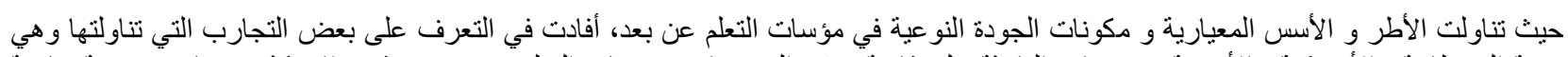

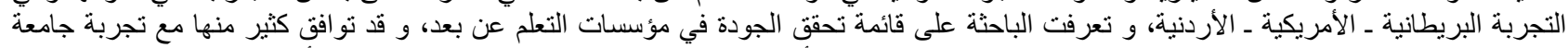

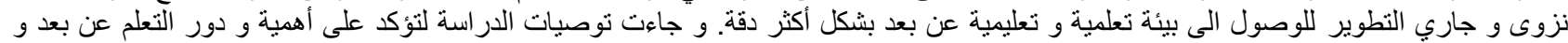
الذي أصبح ملحا مع و بعد كزفيد-19، و وتؤكد الباحثة عليها: ضرورة اتخذا الاجر اءات اللازمة للاعتر اف بهذا النمط من التعليم. ـ ـ ضرورة التوسع في التعلم عن بعد في مؤسسات التعليم العالي.

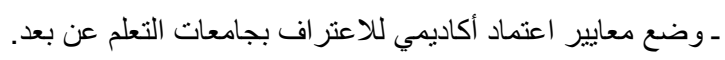
ـ ضرورة متابعة الاشر اف على مؤسسات التعلم عن بعد. ـ دراسة يحيى جابر يحيى البشري: 1996 بعنوان "تتمية القدرات الابداعية ـ دراسة تجريبية على عينة من تلاميذ المرحلة المتوسطة". جامعة الملك سعود.

و فيها اتبع الباحث المنهج شبه التجريبي حيث اختار فصلين دراسيين من أحد المدارس عشو ائيا و طبق على أحدهما (اختبار تور انس للتفكير الابتكاري)

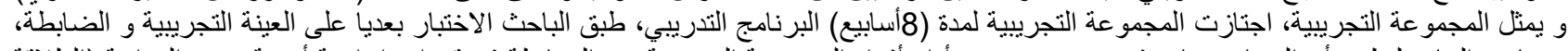

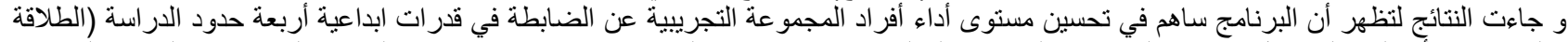

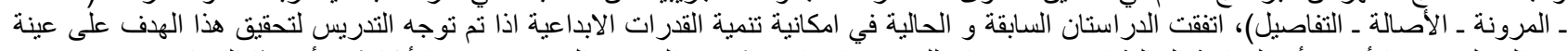

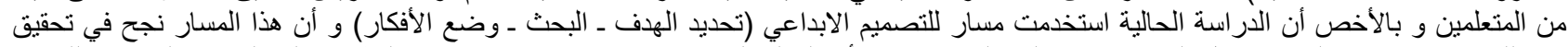

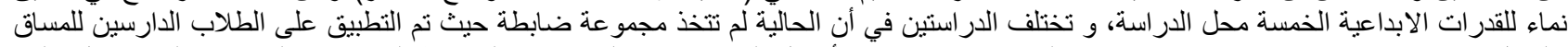

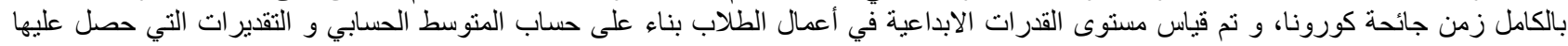
الطلاب من خلال تحكيم مجمو عة من المتخصصين.

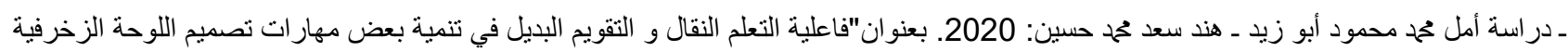
(التصميم الحضري) و بعض مهار ات التقويم البديل لطلاب التربية الفنية".

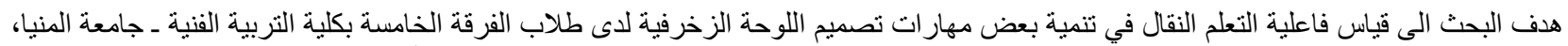

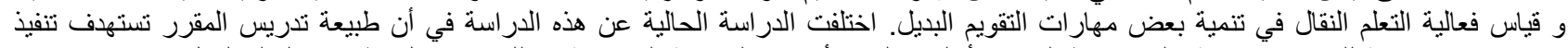

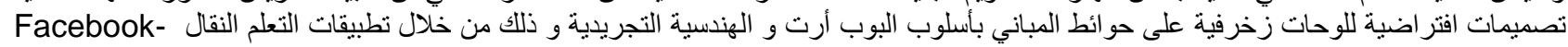
MatsApp- Messenger- Telgram Messenger التطبيق. بينما المقرر في الدراسة الحالية يستهدف تتمية مهار ات التفكير الابداعي و الدهارات اليدوية بالرسم و التلوين بالأسلوب التقليدي. اتفقت الدراستين

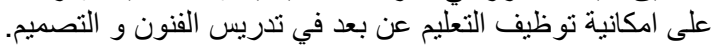
ـ ـ دراسة بيسة عبد الله حامد: 2020. بعنوان "الاستفادة من تكنولو جيات الثورة الصناعية الر ابعة في تدريس مقرر أشغال المعادن عن بعد". 
هدفت الدراسة لتوظيف الامكانات الني حققتها الثورة الصناعية الرابعة في تدريس مقرر أثغال المعادن عن بعد، و تكوين اتجاه ايجابي لطلاب كلية

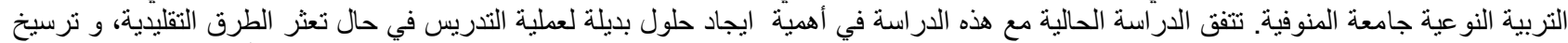

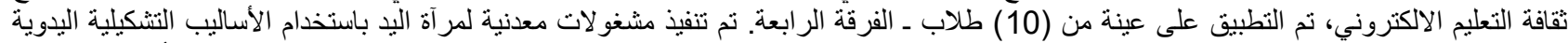

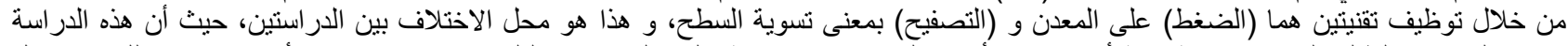

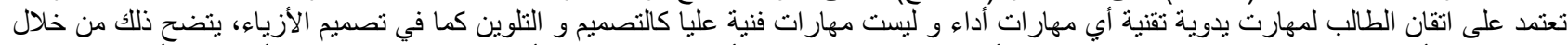

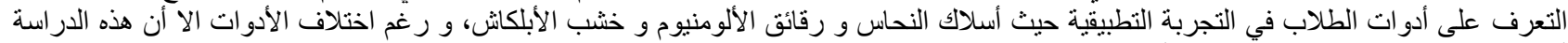
أفادت البحث الحالي في التعرف على الأسلوب الاحصائي الذي تم به معالجة البيانات و التوصل التي التئ النتائج.

2-11- 2-11 التجارب المرتبطة:

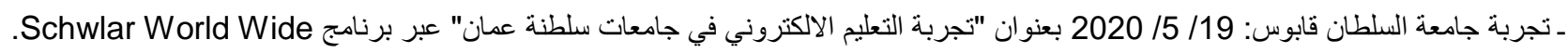

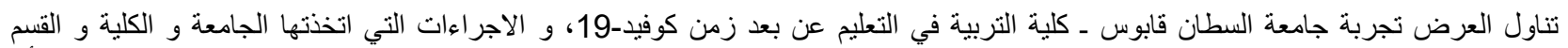

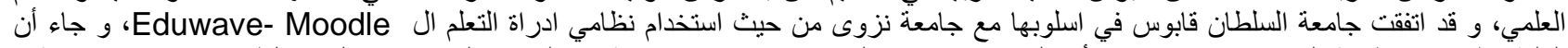

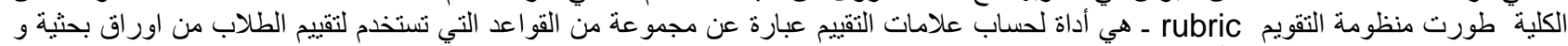

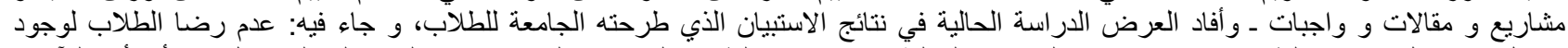

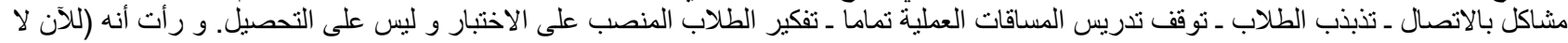

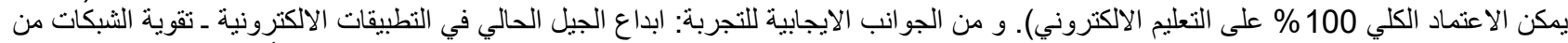

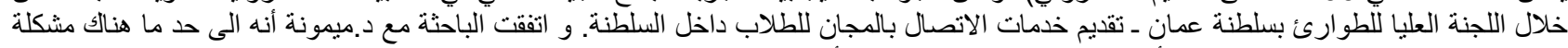

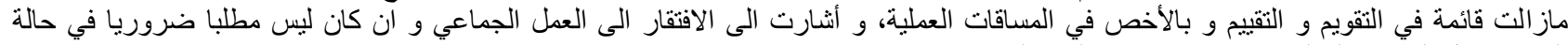
المساق محل الدراسة الحالية. (قدمتها د.ميمونة الزدجالية)

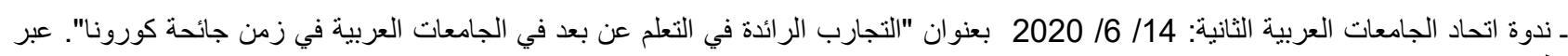
Zoom تطبيق

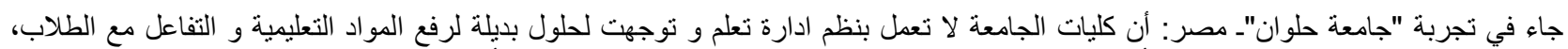

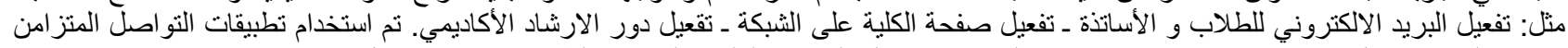
و غير المتزامن مثل zoom- whatsap. و و تم التقييم من خلال البحوث العلمية التي قام الطلاب برفعها في كل مقرر. (قدمها د.ماجد نجم رئيس الجامعة و آخرون)

كذلك قدم رئيس جامعة "آل البيت" ـ الأردن: متابعة ادارة جودة التعلم الالكتروني للمرحلة ـ تسجيل المحاضر اتلات الالكترونية المباشرة ـ اجراء أعمال

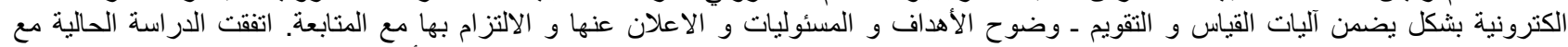

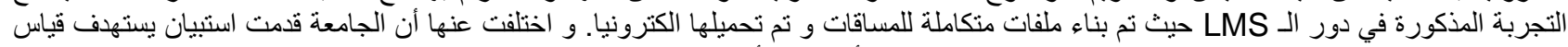
ادارة الجودة للتعلم عن بعد بشكل عام و كاند كانت محاوره عن (الدعم الأكاديمي لأعضاء هيئة التندريس و الطلاب ـ المحتوى الالكتروني ـ الدعم الاداري).

(قدمها د.عدنان العتوم رئيس الجامعة)

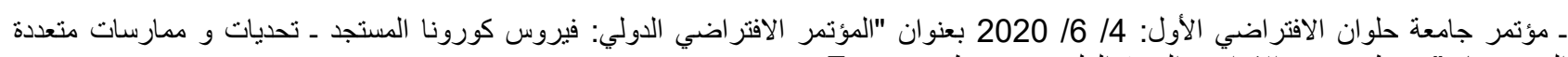

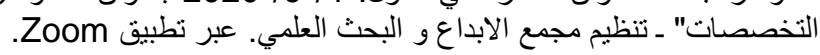

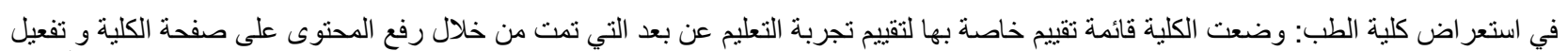

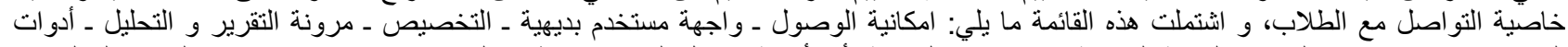

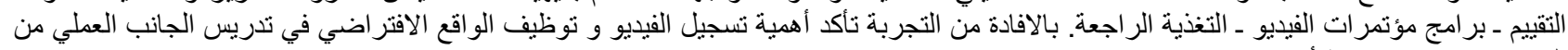
الدقررات. (تقديم د. هبة أمين)

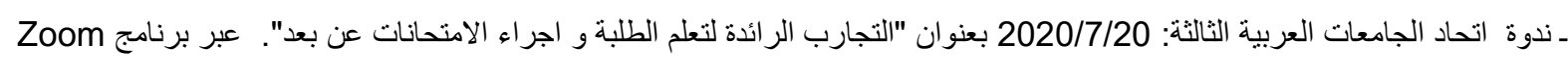

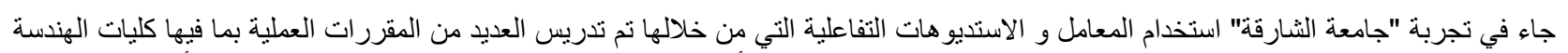

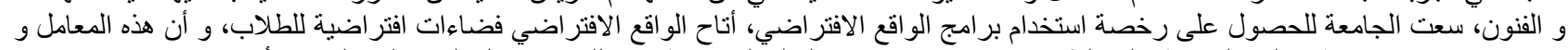

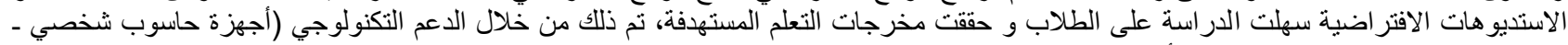

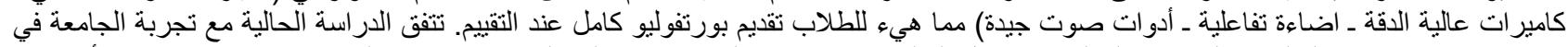

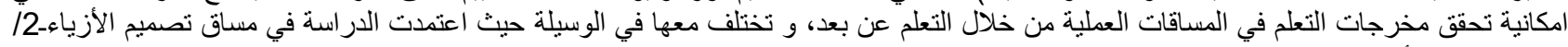

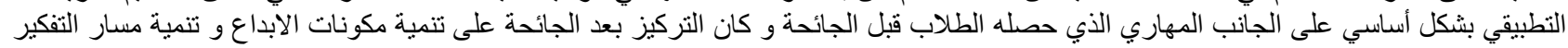

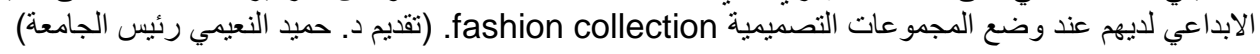

- مؤتمر جامعة Arizona State University عن بعد:2020/7/14-13. بعنوان "The Connected Faculty Summit.

Remote

تم عرض عديد التجارب من مختلف دول العالم في ظل الجائحة المباغتة، كان أكثر ها افادة للار اسة الحالية عرض كلية "Augustana College" و

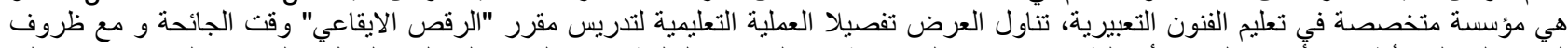

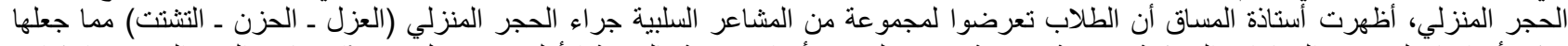

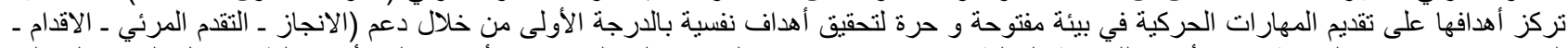

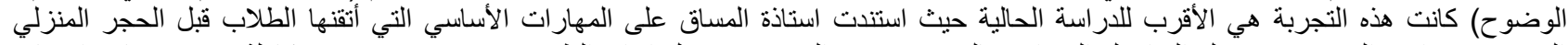

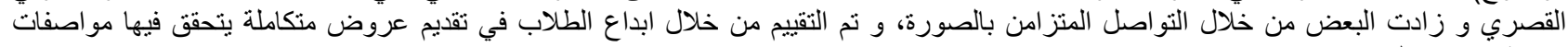

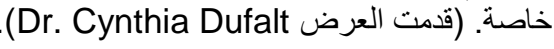


12. ثانيا: المحور الثاني

\section{تجربة جامعة نزوى في التعليم عن بعد وقت جائحة}

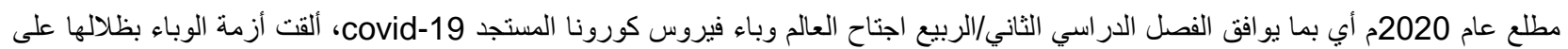

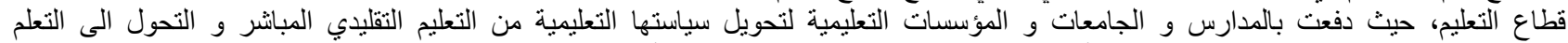

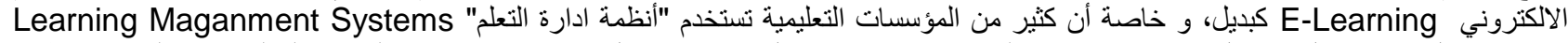

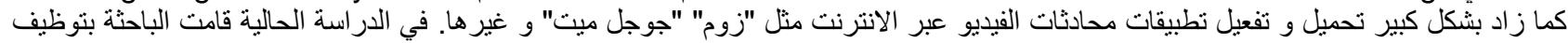

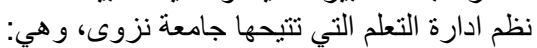

\section{1-12- المنظومة التعليمية الـ Eduwave:}

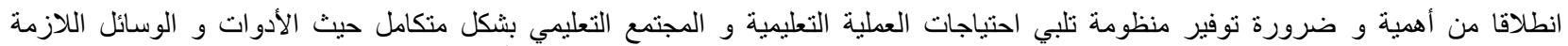

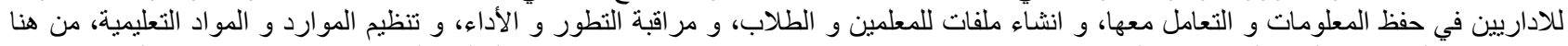

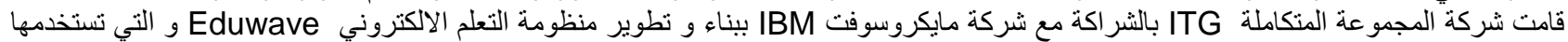

جامعة نزوى في ادارة العملية التعليمية بالجامعة.

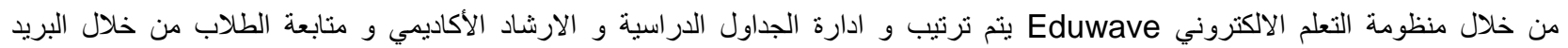

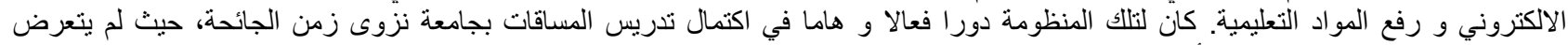

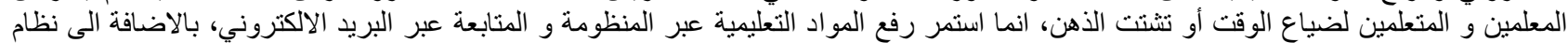

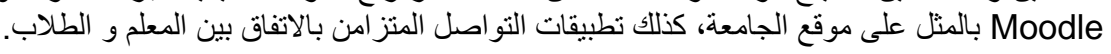

\section{:Moodle 2-12}

كلمة "مودل" اختصار الـ Modular Object Oriented Dynamic Learning Environment.

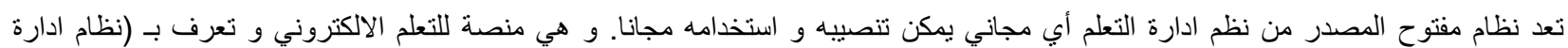

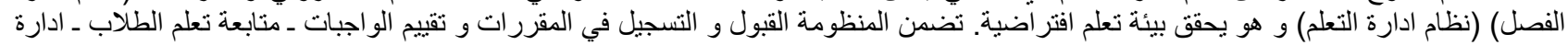

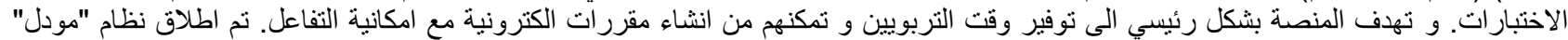

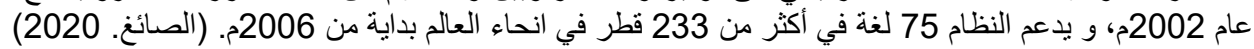

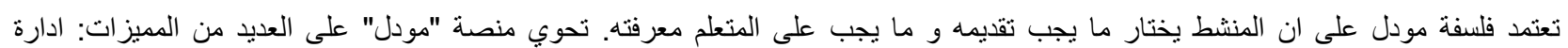

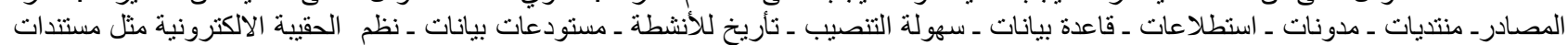

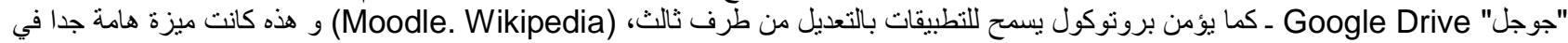
مباغتة التعلم عن بعد زمن كوفيد-19 حيث قامت وحدة (ادارة نظم المعلومات CIS) بجامعة نزوى من تقديم الدعم و التعاون في وضع الاختبار مئرات بصورة نموذجية.

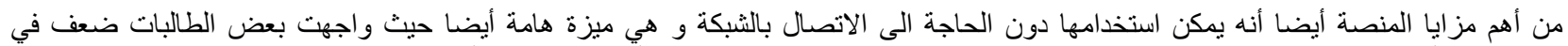

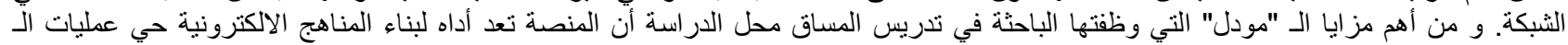

(تجميع - تبويب ـ عرض) (الغريب. 2009).

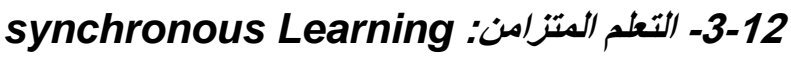

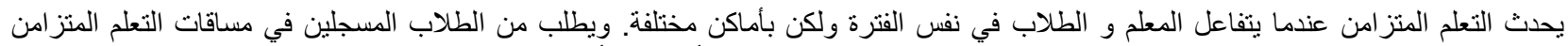

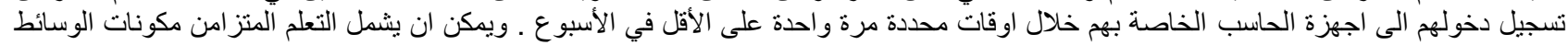
المعتمة مثل ، دردشات المجموعة و الحلقات الدراسية على الثبكة ومؤتمر ات الفيدة الفيديو (عزمي. 2008). ـ الثبكات الحاسوبية و ادارة أنظمة التعلم:

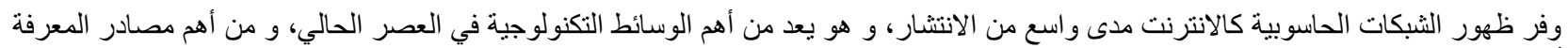

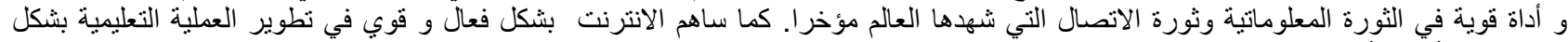
خاص حيث أصبح أداة قوية للتعلم الذاتي و التعلم عن بعد. (الخطيب. 2020) (سافيدار. 2020)

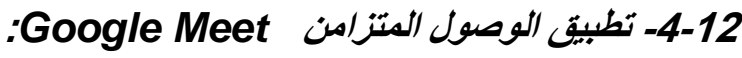

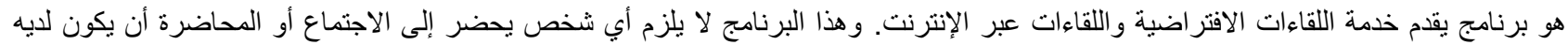

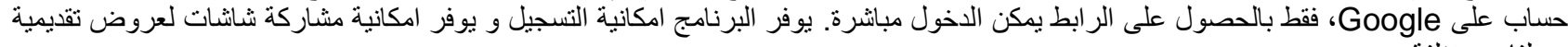
و ملفات مختلفة.

13. ت ثالثا: المحور الثالث

تعزيز مسار التفكير الابداعي لاى الطلاب.

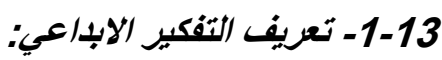

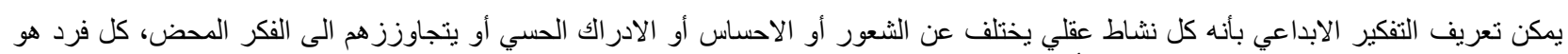
الذي يستخلص المعاني و يعيد تشكيلها في صورة أفكار و رؤى. 
يعرف الابداع بأنه مدى القدرة على التخيل و الاختراع و طرح ما هو غير مسبوق سواء كان ذلك الطرح فكرا أوحلولا أو اعادة اكتشاف لعلاقات و

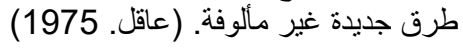

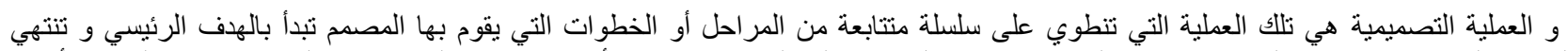

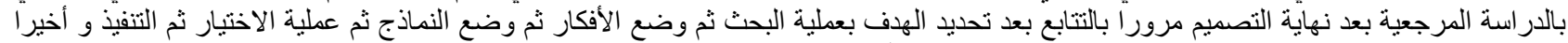

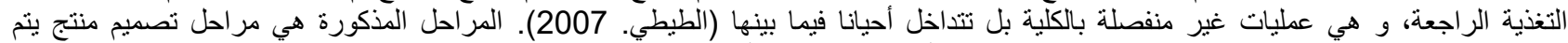

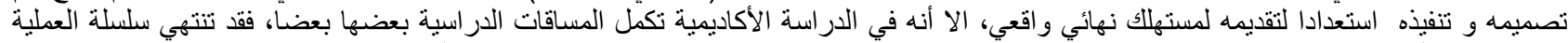

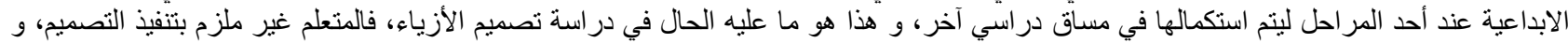

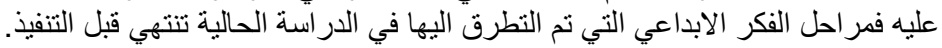

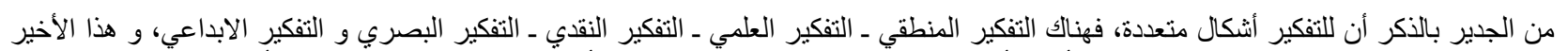

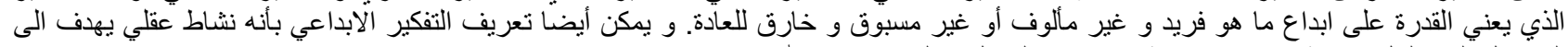

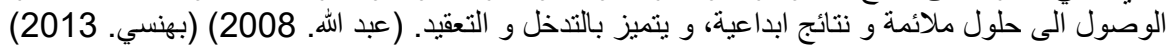

2-13- مراحل التفكبير الابل/عي:

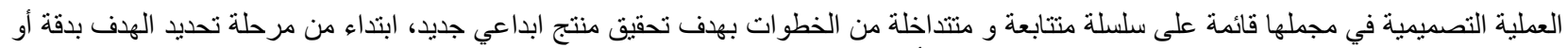

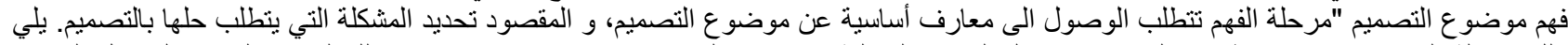

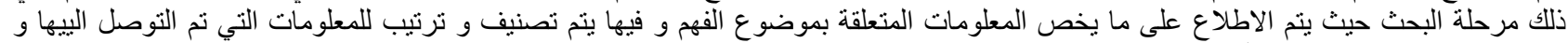

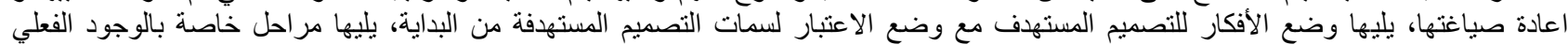

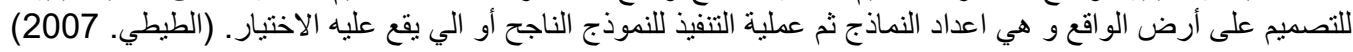

يتضح ان التفكير الابداعي في التصميم يكمن في الاستيعاب الجيد للهدف و ولذول الجئ الجهد الحقيقي مع الالتزام بتتبع الخطوات المتتابعة و التي تتداخل أحيانا

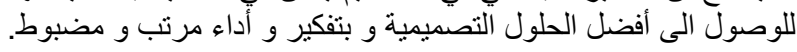

في العرض التالي يتم توضيح اسلوب التفكير الابداعي الذي انبعته الباحثة/ المعلمة في تدريس مساق تصميم الأزياء-2 عن بعد للطالبات التيات في زمن كوفيد-

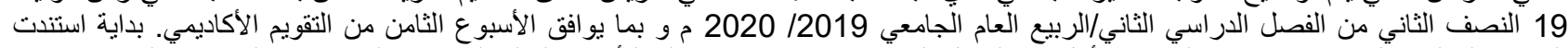

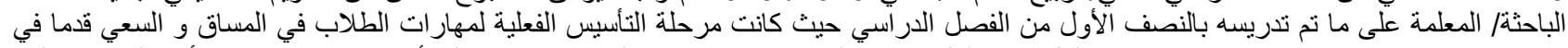

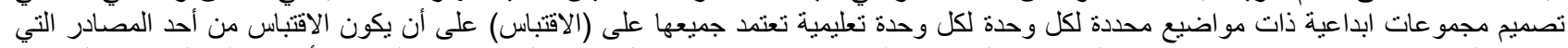

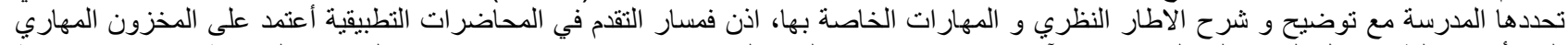

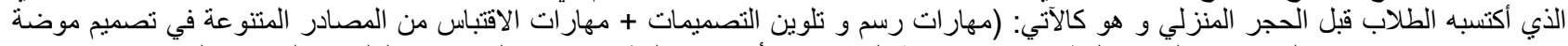

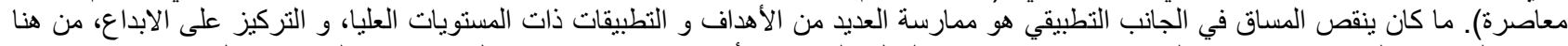

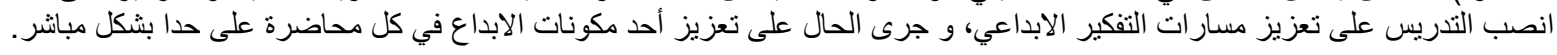

3-13- خطوات التفكير الابل/عي للوحدات الدراسية:

جاءت خطوات التفكير الابداعي للوحدات الدراسية، كالتالي:

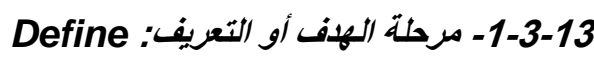

و فيها تحديد الموضوع أو الهدف لكل وحدة بشكل مفصل تدرجا كالآتي:

1ـ تحقيق الطلاقة ـ من خلال ـ موضوع (اقتباس العديد من التصميمات من أعمال مصدم الموضة المعاصرة "الكسندر مكوين" )

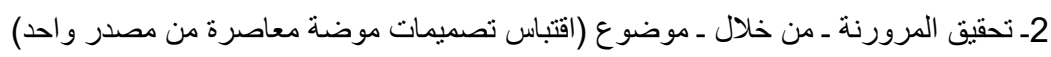
3ـ تحقيق الاهتمام بالتفاصيل ـ من خلال ـ (اقتباس مجموعة تصميمات موضة معاصرة من أحد عروض المصمم "الكسندر مكوين").

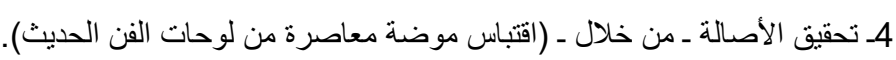

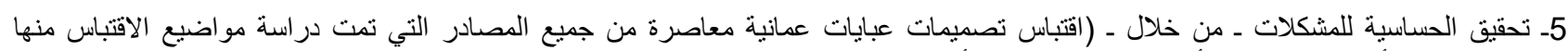

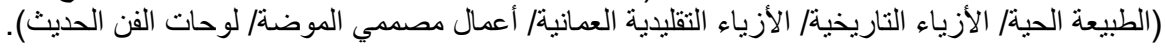
قامت الباحثة/ الأستاذة في كل موضوع بشرح مصدر الأدر الاقتباس في التصميم، و تحليل جمالياته، ثم عرض نماذج من أعمال مصممين موضة قاموا

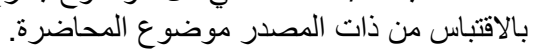

\section{2-3-13 ـ ثانيا: عملية البحث: Research}

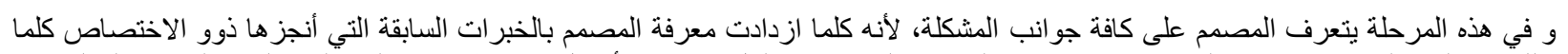

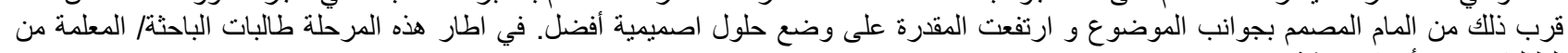

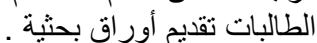

\section{Ideate :-3-13- ثالثا: وضع الأفكار}

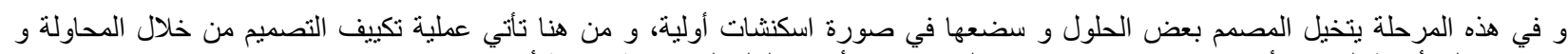

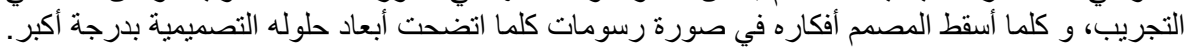


يلي تلك المراحل مجموعة أخرى تتعلق بعملية تنفيذ التصميمات من سلسلة التفكير الابداعي الا أن الدراسة الحالية لم تتعرض اليها، و هي (وضع

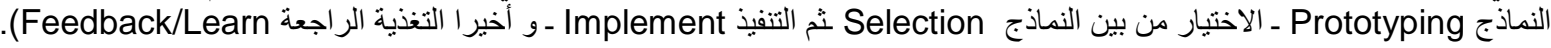
أثناء التدريس قام الطلاب بوضع الاسكتشات و ارسالها عبر الـ Moodle و عبر البريد الاكتروني، تم تقييمها بهدف الوصول لنتائج الدراسة الحالية، ثم توجيه الطلاب لتصوي فيبها.

\section{Creativity Abilities}

تناولت الدر اسة أربعة القدرات الابداعية أو مكونات الابداع (الطيطي. 2007) (بهنسي. 2013) كما يطلق عليها أحيانا، و هي كالتالي: ـ طلاقة المصمم: Fluency

تعني طلاقة المصمح القدرة على انتاج أكبر عدد من الأفكار في وقت واحد، أي استحضار أكبر قدر ممكن من الأفكار و التصميمات ضمن فترة زمنية

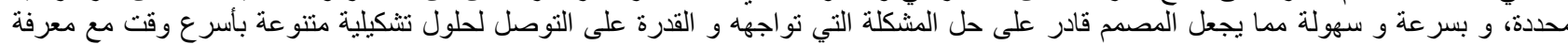
تفصيلية بالخامات و امكانياتهاو و استخداماتها.

ـ مرونة المصدم: Flexibility

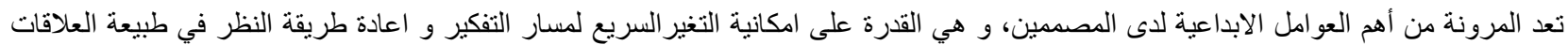

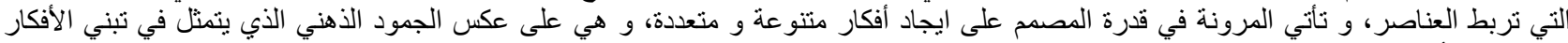
التقليدية و الأفكار الثابتة و التي يمكن التنبؤ بها سلفاو فيرة فير فابلة للتغيير.

و للمرونة انبين أساسيين: 1) القدرة التحليلية للعلاقات و تعتمد على قدرة المصدم على تغيير طريقة التفكير و بناء التهل الحل باعنبار المشكلة هي الدافع. 2)

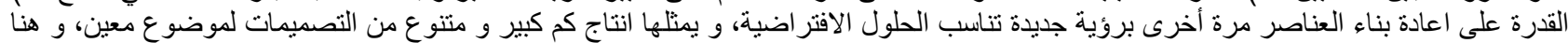

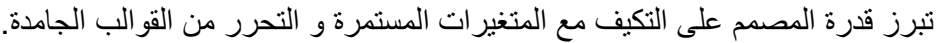

ـ أصالة المصمم: Originality

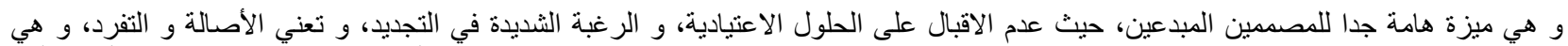

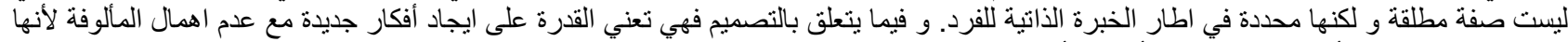
قد تكون مصدر ايحاء أو الهام للوصول فئول للأفكار الأكثر تقدما.

ـ الحساسية للمشكلات: Sensitivity

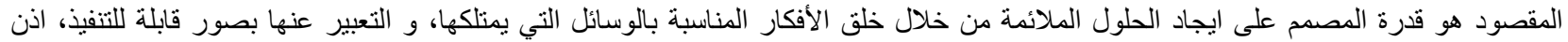

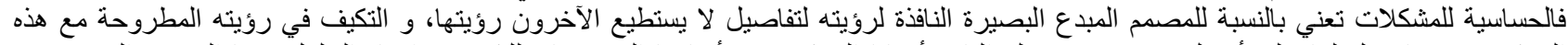

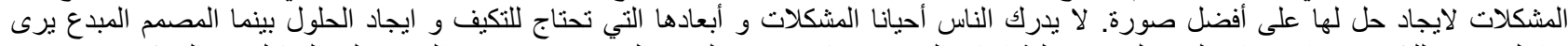

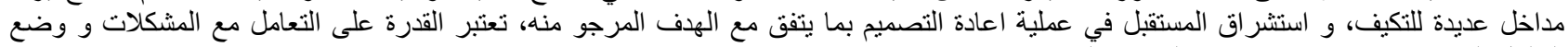

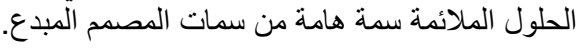

ـ الاهتمام بالتفاصيل: Elaboration

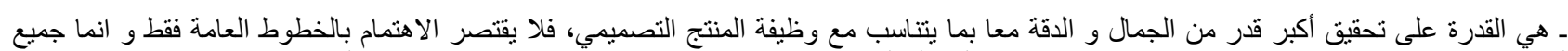

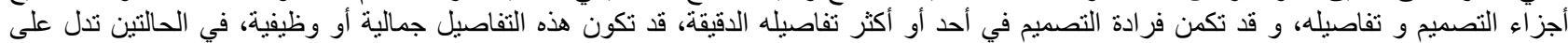
اهتمام المصمم بأدق التفاصيل أب الالمام الكامل بالحلول التصميمية المقترحة من جميع جو انبها. (خصاونة.

\section{4 -رابعا: المحور الرابع باني}

\section{-الوحدات التعليمية المقترحة لتعزيز القدرات الابداعية:}

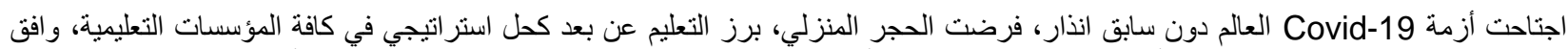

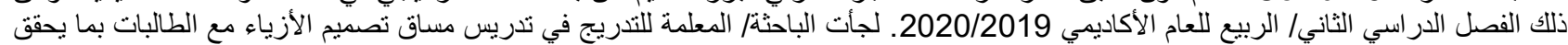
مخرجات التعلم الخاصة ببرنامج الفنون الجميلة بشكل عام ـ تخصص الإني تصميم الأزياء و بشكل خاص مساق تصميم الأزياء-2 / التطبيقي و النظري.

\section{1-14- الدراسة قبل العجر المنزلي (التعليم المباشر):}

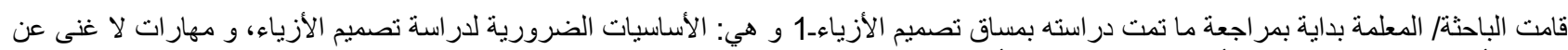

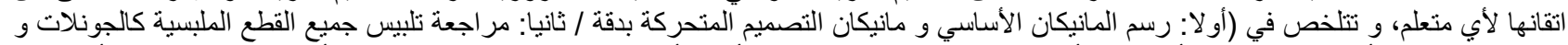

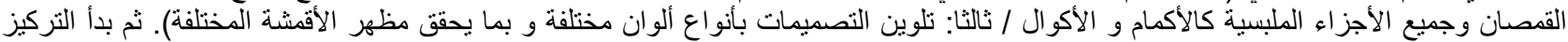

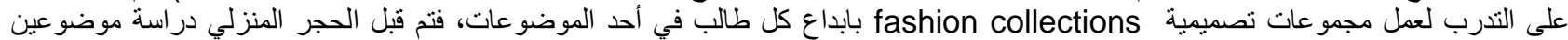
نظريين، يقابلهم نفس الموضوع مجوع في التطبيق العملي، و هما:

ـاقتباس موضة معاصرة مصادر الطبيعة الحية:

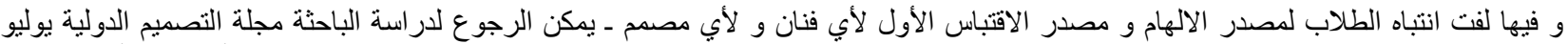

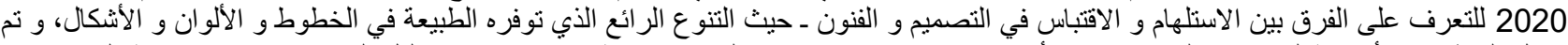

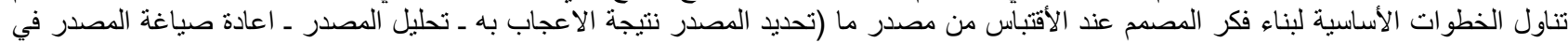

صورة تصميم موضة معاصرة الاصنية لبناء فكرة 
-اقتباس تصميم موضة معاصرة من الأزياء التاريخية:

و فيها توجيه الطلاب الى أن مصمم الموضة يمنالك منبعا خصبا يميزه عن غيره من المصممين في مجالات التصميم المختلفة، ألا و هو الأزياء ذاتهاو

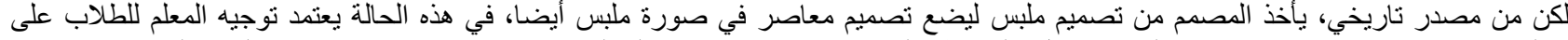

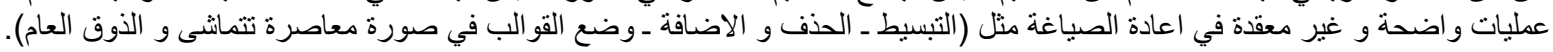

$$
\text { ـاقتباس تصميم موضة معاصرة من الأزياء التقليدية العمانية: }
$$

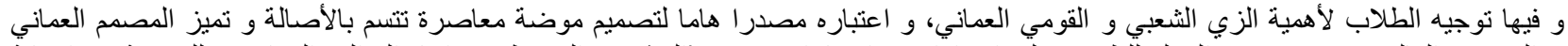

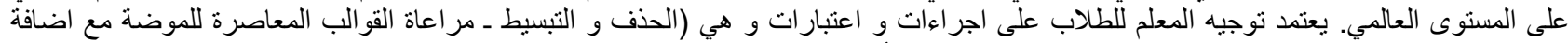

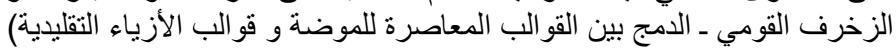

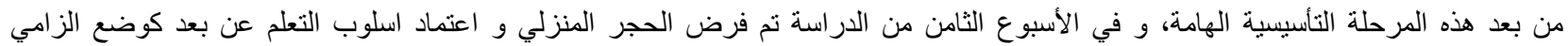

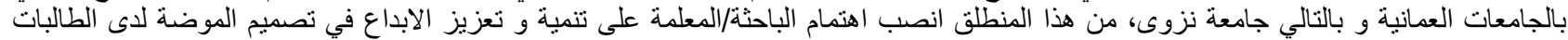

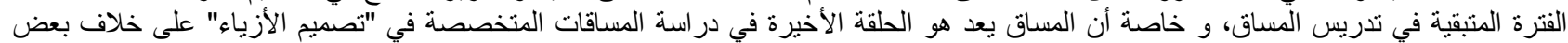

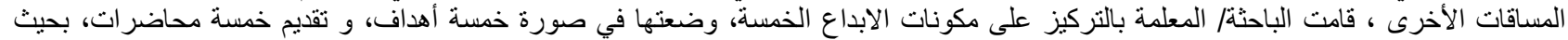

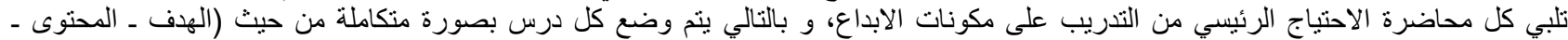

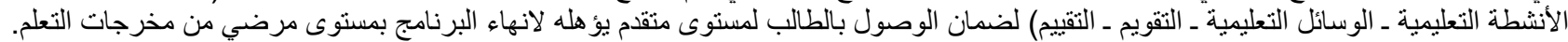

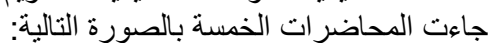

\section{2-14-الدراسة بعد الحجر المنزلي: التعليم عن بعد:}

وجدت الباحثة أن تتمية القدر ات الابداعية لاى الطلاب كانت ستأتي بشكل ضمني أثناء المحاضرات و و مع التوجيه و التو اصل المباشر بين الأستاذة و

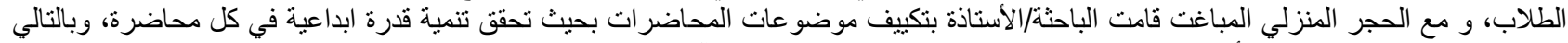

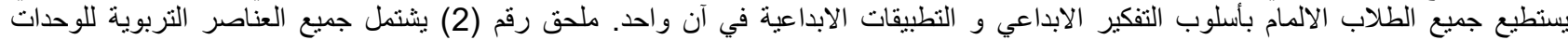

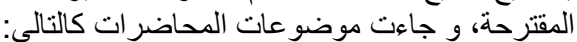

ـ المحاضرة الأولى: تحقيق (الطلاقة). موضوع الهو المحاضرة: الاقتباس من تصميمات مصمم الموضة المعاصرة "الكسندر مكوين" ـ عديد من التصميمات

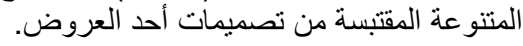

ـ المحاضرة الثانية: تحقيق (المرونة). موضوع المحاضرة: الاقتباس المتنوع من تصميم واحد تحديدا. ـ المحاضرة الثالثة: تحقيق (ادر الك التفاصيل). موضوع المحاضرة: اقتباس مجموعة تصميمات موضة معاصرة من أحد عروض المصمم "الكسندر مكوين"

ـ المحاضرة الر ابعة: تحقيق (الأصالة). موضوع المحاضرة: اقتباس موضة معاصرة من لوحات الفن الحديث.

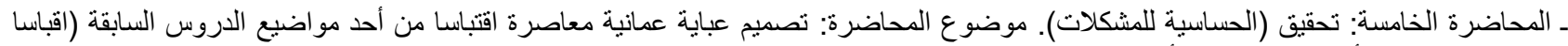

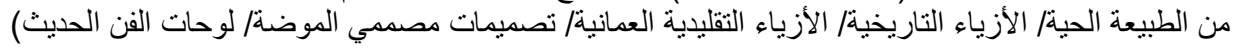

15

\section{مقياس اتجاهات الطلاب نحو التعليم عن بعد زمن كوفيد-19 في مساق (تصميم الأزياء-2 ).}

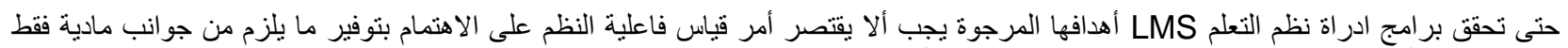

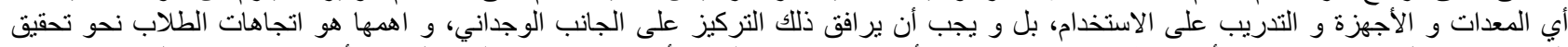

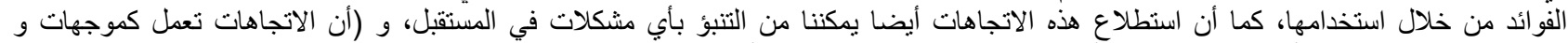

متتبئات للسلوك، و خاصة أن التوجه العام بعد أزمة كوفيد-19 الى التهات التعلم المدمج أو الهجين) (Reid. 2007).

تم تصميم مقياس اتجاهات لاستطلاع اتجاهات الطلاب نحو التعليم عن بعد لمساق تصميم الأزياء-2/التطبيقي زمن جائحة كوفيد-19، و تألفت من (20) فقرة و تم تطبيقها على (20) طالبة.

توز عت فقرات المقياس لمحورين أساسيين، هي:

ـ المحور الأول: الرغبة و الاستمتاع بتجربة تعليم تصميم الأزياء-2/ التطبيقي.

ـ المحور الثاني: تقدير قيمة و أهمية التعليم عن بعد في مجال تصميم الموضة.

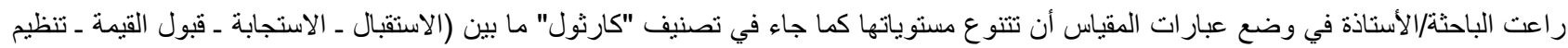

الاتجاهات ـ الاعتزاز بالقيمة).

16 نتائج الدراسة: 


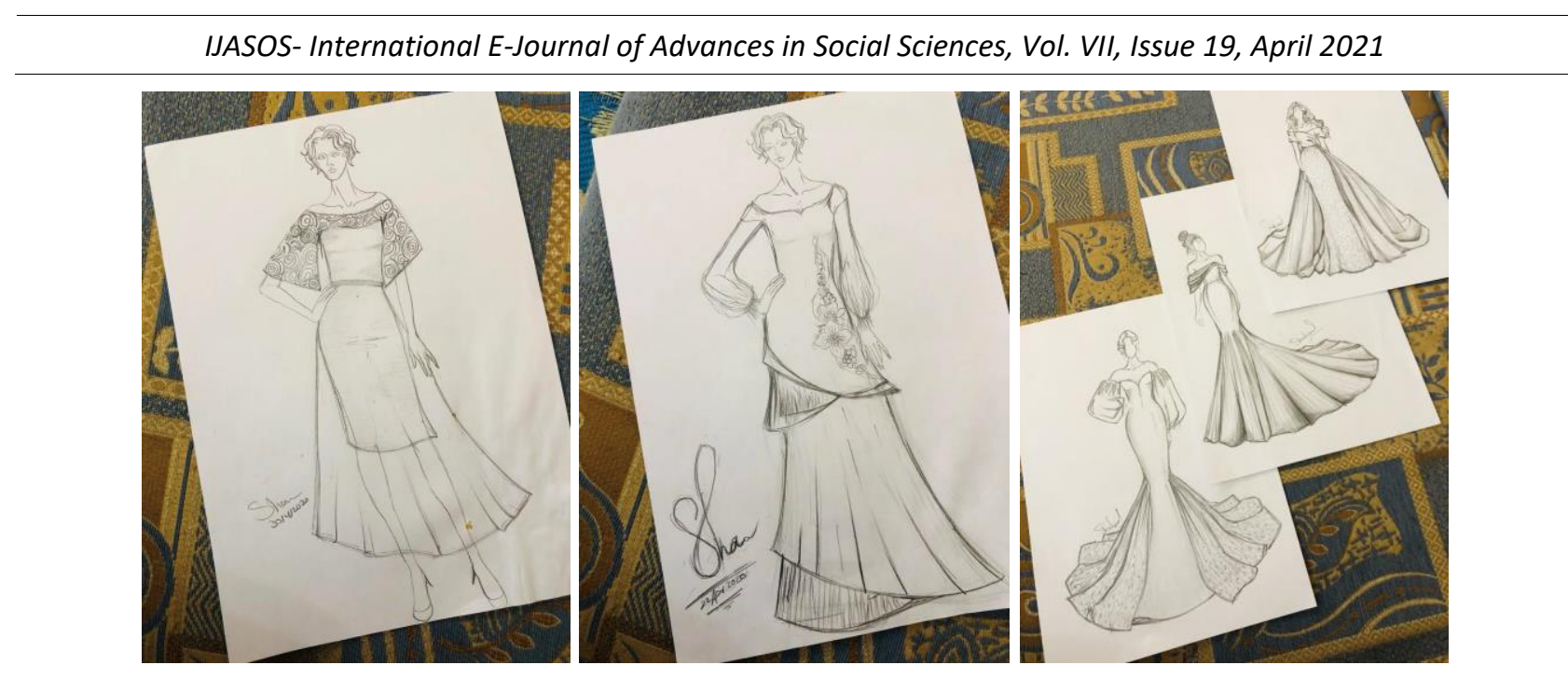

الصور (1: 3): اسكتثات توضح (الطلاقة) في وضع العديد من الأفكار لموضوع واحد، و (المرونة) لوضع العديد من الحلول للفكرة الواحدة. الطالبة شهذ سعيد
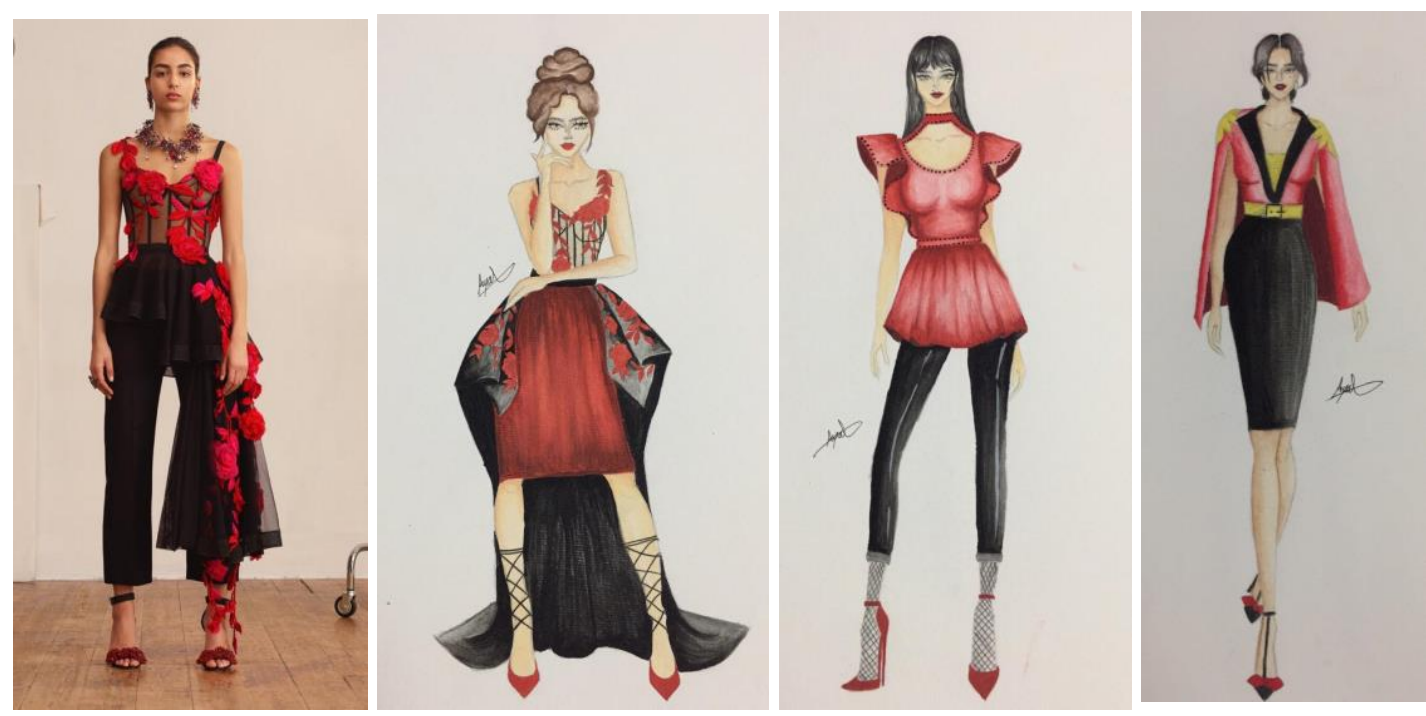

الصور(4: 7) بعض الاسكتثات التي توضح تنمية قدرات (المرونة)-(ادارك التفاصيل). الطالبة آيات عبد الله
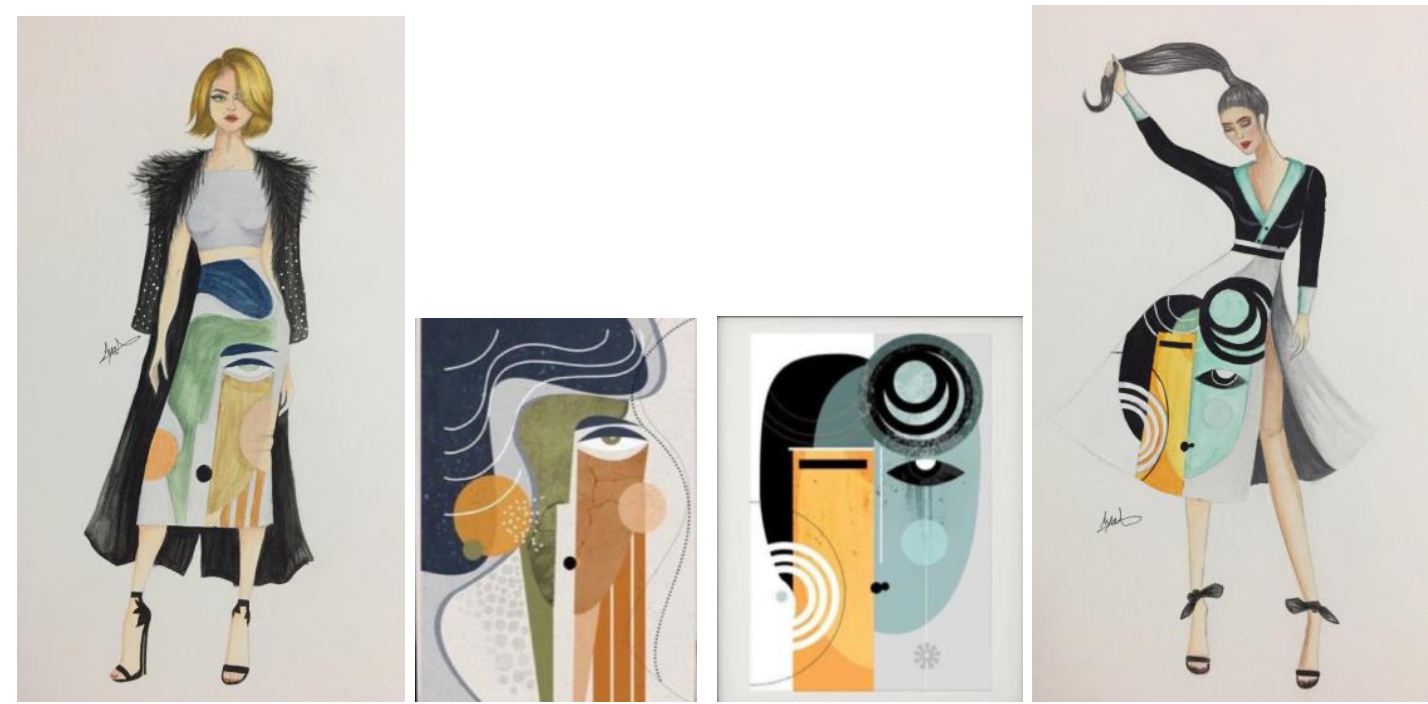

الصور(8: 11) :بعض الاسكتشات التي توضح تنمية قدرة (الأصالة). الطالبة آيات عبد اله 

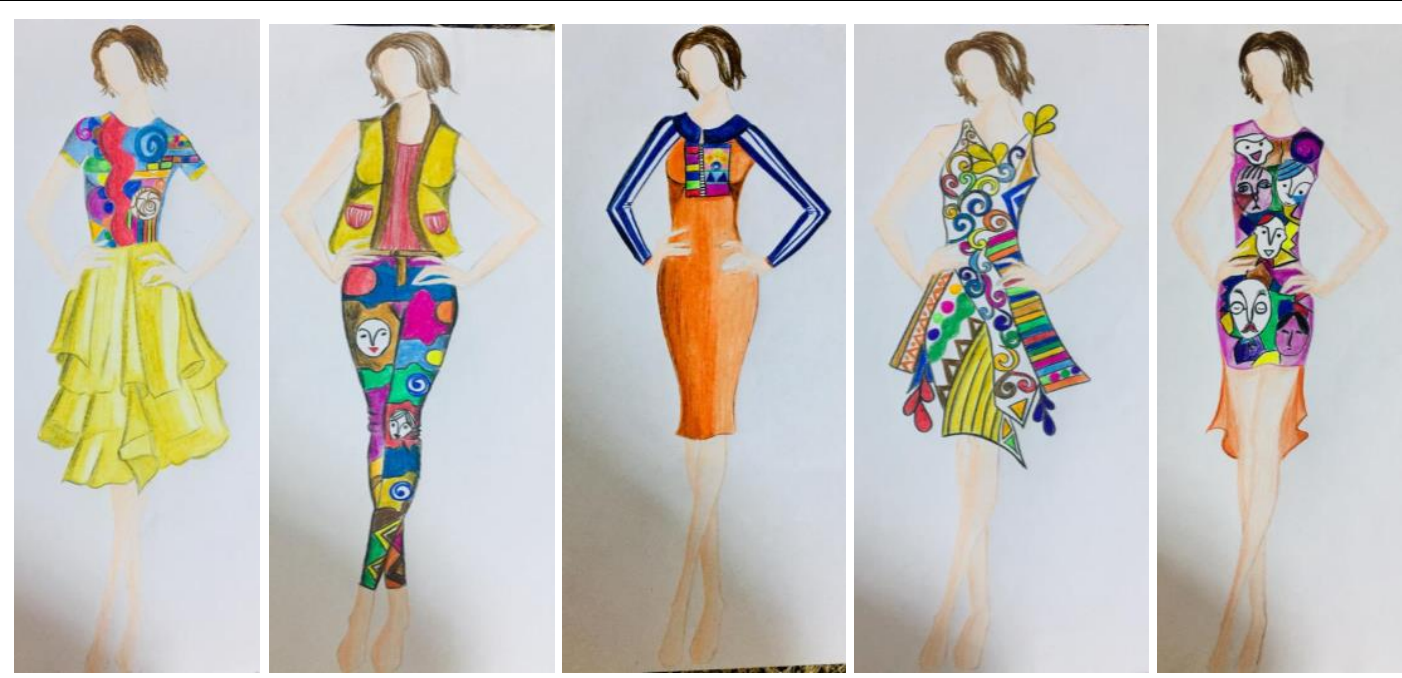

الصور (12: 16):بعض الاسكتشات التي توضح تتمية قدرة (ادر اك التفاصسل). الطالبة أماني هشيل

\section{7 تحليل النتائج و تفسير ها (الاطار الاحصاني):}

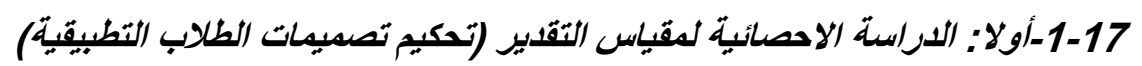

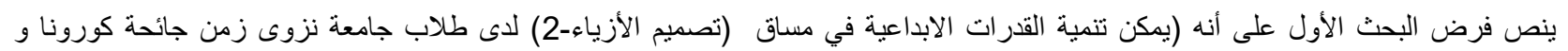

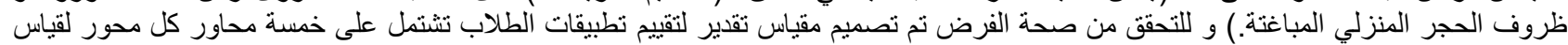

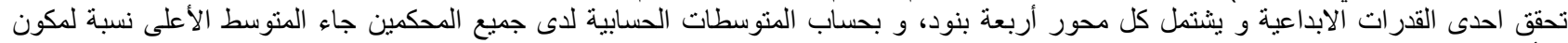

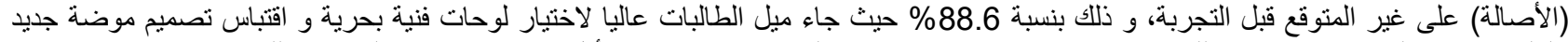

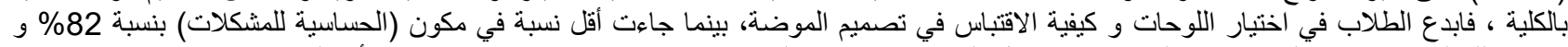

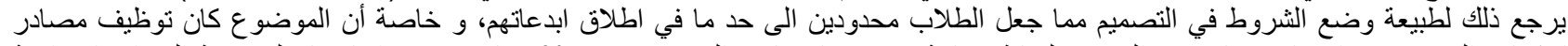

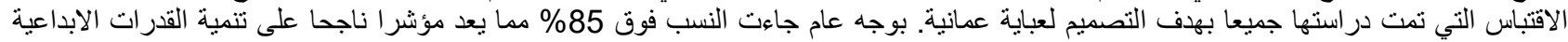
لاى الطلاب في السساق محل الدراسة وقت جائحة كوفيد-19 العام الدراسي 2020م. الجداول التالية توضح ملخص متوسط التقديرات و النسب المئوية لكل محور /قدرة ابداعية:

جدول(1) يوضح ملذص متوسط التقيرات و النسب المئوية لبنود المحور الأول (الطلاقة) عند المحكمين

\begin{tabular}{|c|c|c|}
\hline النسبة & 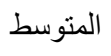 & بنود المحور \\
\hline$\% 91$ & 4.55 & 1-التصميمات المقترحة تحقق اقتباسا ناجحا من المصدر محل الاقتباس. \\
\hline$\% 80$ & 4.02 & 2-تم توظيف عناصر التصميم (خطوط ـ مساحات ـ الوان) في وضع تصميم ناجح لموضة \\
\hline$\% 86.4$ & 4.32 & 3-تم توزيع عناصر التصميم داخل التصميم من خلال أسس تكوين (وحدة ـ اتزان ـ تناسب ـ \\
\hline$\% 80.2$ & 4.01 & 4-العدد الكقدم يعبر عن طلاقة فكر الطالب/الدصمم (لا يقل عن عشر تصميمات). \\
\hline$\% 84$ & 4.2 & متوسط المجموع \\
\hline
\end{tabular}

ـ المحور الثاني الخاص بقدرة (المرونة) نجد انها جاءت بنسبة (87.1\%) تقريبا، مما يؤكد على نجاح التجربة التطبيقية في تنمية قدرة الطلاب في وضع

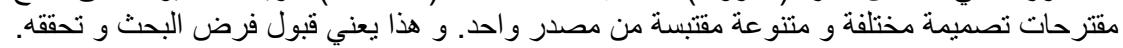

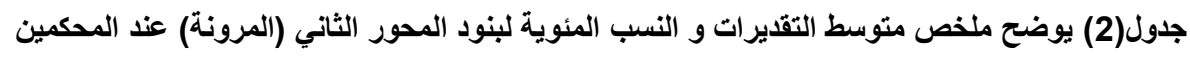

\begin{tabular}{|c|c|c|}
\hline 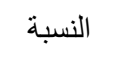 & 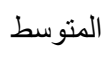 & بنود المحور \\
\hline$\% 86.4$ & 4.32 & 1-التصميمات المقترحة تحقق اقتباسا ناجحا من المصدر محل الاقتباس. \\
\hline$\% 91$ & 4.55 & 2-تم توظيف عناصر التصميم (خطوط ـ مساحات ـ الوان) في وضع تصميم ناجح لموضة \\
\hline
\end{tabular}


IJASOS- International E-Journal of Advances in Social Sciences, Vol. VII, Issue 19, April 2021

\begin{tabular}{|c|c|c|}
\hline$\% 85.4$ & 4.27 & 3-تم نوزيع عناصر التصميم داخل التصميم من خلال أسس تكوين (وحدة ـ اتزان ـ تناسب ـ \\
\hline$\% 85.6$ & 4.28 & 4- التصميمات المقترحة تتميز بكونها أفكار غير اعتيادية. \\
\hline$\% 87.1$ & 4.35 & المجموع \\
\hline
\end{tabular}

ـ المحور الثالث الخاص بقدرة (ادر الك التفاصيل) نجد انها جاءت بنسبة (85\%) تقريبا، مما يؤكد على نجاح التجربة التطبيقية في تتمية قدرة الطلاب في

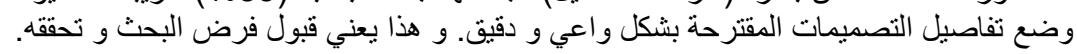

جدول(3) ملخص متوسط التقديرات و النسب المئوية لبنود المحور الثالث (ادراك التفاصيل) عند المحكمين

\begin{tabular}{|c|c|c|}
\hline 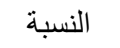 & 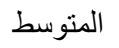 & 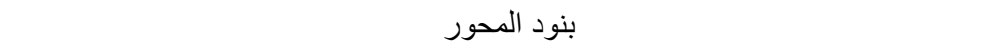 \\
\hline$\% 80.2$ & 4.01 & 1-التصميمات المقترحة تحقق اقتباسا ناجحا من المصدر محل الاقتباس. \\
\hline$\% 85.6$ & 4.28 & 2-نم نوظيف عناصر التصميم (خطوط ـ مساحات ـ الوان) في وضع تصميم ناجح لموضة \\
\hline$\% 82.6$ & 4.13 & 3-نم توزيع عناصر التصميم داخل التصميح من خلال أسس تكوين (وحدة ـ اتزان ـ تناسب ـ ـ ائسلوب \\
\hline$\% 91.2$ & 4.56 & 4-التصميمات المقترحة تتميز بأكبر قدر من الدقة و الجمال و وضوح التفاصيل . \\
\hline$\% 85$ & 4.25 & 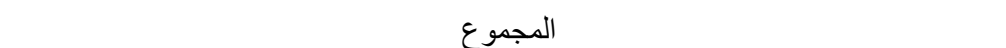 \\
\hline
\end{tabular}

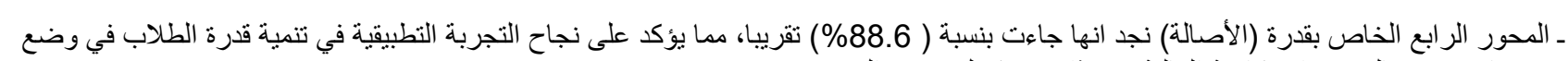

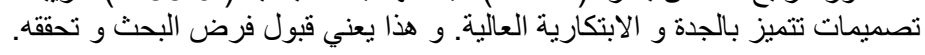

جدول(4) يوضح ملخص متوسط التقديرات و النسب المئوية لبنود المحور الرابع (الأصالة) عند المحكمين

\begin{tabular}{|c|c|c|}
\hline النسبة & 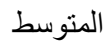 & 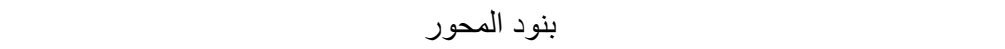 \\
\hline$\% 84.4$ & 4.22 & 1-التصميمات المقترحة تحقق اقتباسا ناجحا من المصدر محل الاقتباس. \\
\hline$\% 92.6$ & 4.63 & 2-تم توظيف عناصرة التصميم (خطوط ـ مساحات ـ الوان) في وضع تصميم ناجح لموضة \\
\hline$\% 93$ & 4.65 & 3-تم توزيع عناصر التصميج داخل التصميم من خلال أسس تكوين (وحدة ـ اتزان ـ تناسب ـ \\
\hline$\% 84.4$ & 4.22 & 4-التصميمات المقترحة تمثل أفكار ا معاصرة لعباءة عمانية قابلة للتنفيذ و التسويق . \\
\hline$\% 88.6$ & 4.43 & 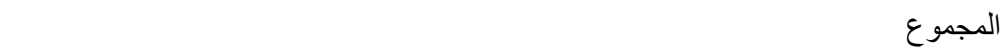 \\
\hline
\end{tabular}

المحور الخامس الخاص بقدرة (الحساسية للمشكلات) نجد انها جاءت بنسبة (82\%) نقريبا، مما يؤكد على نجاح التجربة التطبيقية في تنمية قدرة الطلاب

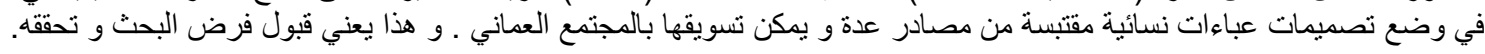
جدول(5) ملخص متوسط التقديرات والنسب المئوية لبنود المحور الخامس (الحساسية للمشكلات) عند المحكمين

\begin{tabular}{|c|c|c|}
\hline 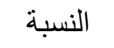 & 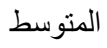 & 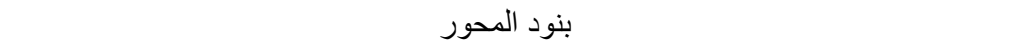 \\
\hline$\% 82.6$ & 4.13 & 1-التصميمات المقترحة تحقق اقتباسا ناجحا من المصدر محل الاقتباس. \\
\hline$\% 80$ & 4 & 2-نم توظيف عناصر التصميم (خطوط ـ مساحات ـ الوان) في وضع تصميم ناجح لموضة \\
\hline$\% 85.4$ & 4.27 & 3-نم توزيع عناصر التصميم داخل التصميم من خلال أسس تكوين (وحدة ـ اتزان ـ تناسب ـ \\
\hline
\end{tabular}




\section{IJASOS- International E-Journal of Advances in Social Sciences, Vol. VII, Issue 19, April 2021}

\begin{tabular}{|c|c|c|}
\hline & & ايقاع) بأسلوب ناجح. \\
\hline$\% 80.4$ & 4.02 & 4-التصميمات المقترحة تشكل تنو عا واضحا فيما بينها رغم اقتباسها من ذات المصدر/التصميم \\
\hline$\% 82$ & 4.1 & المجموع \\
\hline
\end{tabular}

مما جاء في نتائج التحليل الاحصائي يتبين: ـ تحقق تأثير فعال في تدريس مساق (تصميم الأزياء) و تتمية التفكير الابداعي و القدرات الابداعية لدى الطلاب، و انه أمكن الحصول على المعارف و

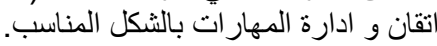

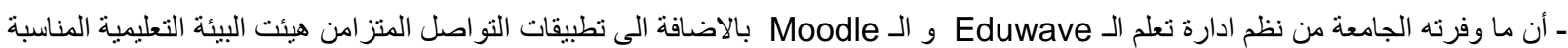
لتخطي الأزمة و تحصيل الطلاب لمخرجات التعلم، كما تحققت القدرة على التقييم الطلاب طبقا للفروق الفردية.

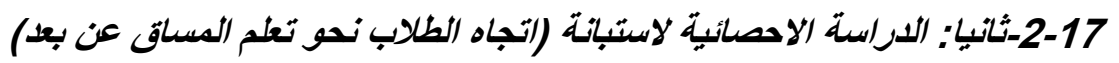

ينص فرض البحث الثاني على أنه (يمكن تنمية الاتجاه الايجابي للطلاب نحو در اسة مساق "تصميم الأزياء-2" عن بعد من خلال نظم ادارة التعلم و تطبيق

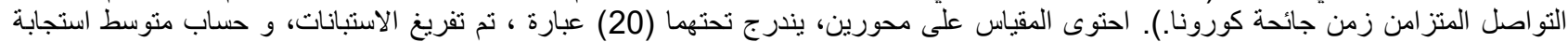

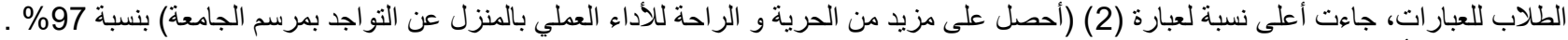

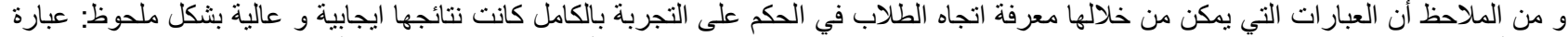

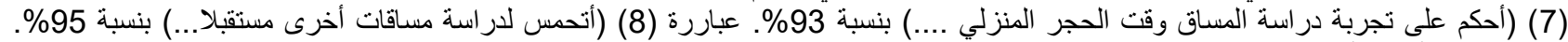

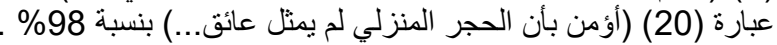

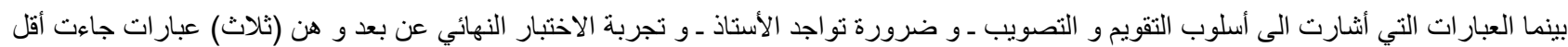

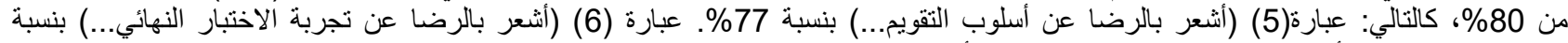

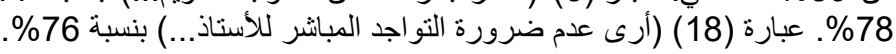

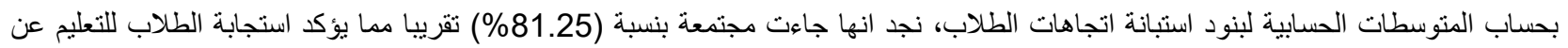

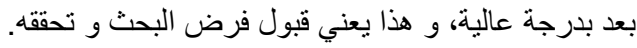

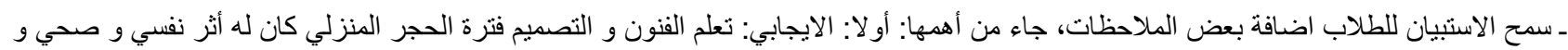

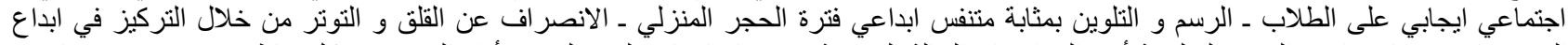

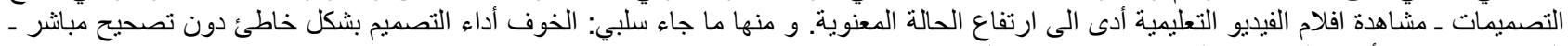
التردد في وضع الأفكار المبتكرة ـ التخوف من الاختبنة النقار النهائي.

جدول (6) المتوسط الحسابي و النسب المئوية لاتجاه الطلاب نحو تعليم (تصميم الأزياء) عن بعد زمن الجائحة

\begin{tabular}{|c|c|c|c|c|}
\hline الترتيب & النسبة & 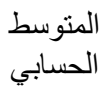 & 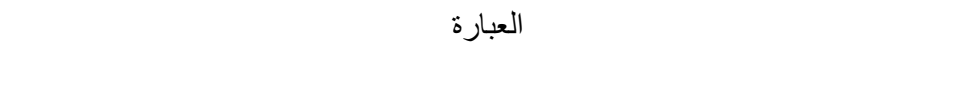 & 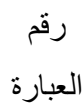 \\
\hline & & & \multicolumn{2}{|l|}{ المحور الأول: الرغبة و الاستمتاع بتجربة تعليم (تصميم الأزياء-2). } \\
\hline 5 & $\% 90$ & 4.5 & أتقبل تعديل المحتوى بالخطة الدر اسية لمساق (تصميم الأزياء-2) فترة الحجر المنزلي . & 1 \\
\hline 2 & $\% 97$ & 4.85 & أحصل على مزيد من الحرية و الر احة للأداء العملي بالمنزل عن التو اجد بمرسم الجامعة. & 2 \\
\hline 13 & $\% 80$ & 4 & أحاول انجاز التكليفات من واجبات و غير ها على أفضل مستوى. & 3 \\
\hline 10 & $\% 83$ & 4.15 & أثعر بالرضا عن أداء المعلم في تدريس المساق. & 4 \\
\hline 14 & $\% 77$ & 3.85 & أثنعر بالرضا عن الاسلوب الذي صوبت به أستاذة المساق لأخطائي في التصميح & 5 \\
\hline 15 & $\% 78$ & 3.9 & أشعر بالرضا عن تجربة الاختبار النهائي/ التطبيقي للمساق. & 6 \\
\hline 4 & $\% 93$ & 4.65 & أحكم على تجربة دراسة مساق (تصميم الأزياء-2) أثناء الحجر بأنها ناجحة و ممتعة. & 7 \\
\hline 3 & $\% 95$ & 4.75 & أتحمس لدر اسة مساقات عملية جديدة مستقبلا من خلال اسلوب التعليم عن بعد. & 8 \\
\hline
\end{tabular}


IJASOS- International E-Journal of Advances in Social Sciences, Vol. VII, Issue 19, April 2021

\begin{tabular}{|c|c|c|c|c|}
\hline & & & المحور الثاني: تقدير قيمة و أهمية التعليم عن بعد في مجال تصميم الأزياء. & \\
\hline 11 & $\% 82$ & 4.10 & أتفهم بوضوح الأهداف المنشود تحقيقها من دراسة المساق حتى نهاية الفصل الدراسي. & 9 \\
\hline 12 & $\% 81$ & 4.05 & أتحمس لأداء الأنشطة التعليمية المطلوب انجاز ها. & 10 \\
\hline 8 & $\% 86$ & 4.3 & أعزز مهار اتي من خلال مشاهدة المزيد من مقاطع الفيديو على الثبكة. & 11 \\
\hline 10 & $\% 83$ & 4.15 & أمارس بشغف المزيد من المهار ات التي ترتقي بمستو اي في الرسم و التصميم. & 12 \\
\hline 6 & $\% 89$ & 4.45 & 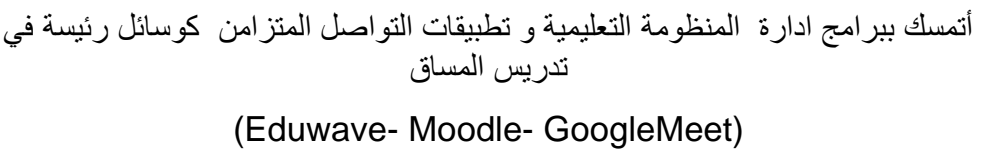 & 13 \\
\hline 7 & $\% 88$ & 4.4 & أنسق مع الأستاذة تقديم التكاليف بمرونة و بما يوافق الظروف المرتبطة بالحجر المنزلي. & 14 \\
\hline 9 & $\% 84$ & 4.2 & أنعاون مع زملائي في تبادل المعلومات حول الأنشطة و الو اجبات المطالبة بها في & 15 \\
\hline 6 & $\% 89$ & 4.45 & أصوب التصميمات المقدمة للتقييم بناء على توجيهات أستاذة المساق. & 16 \\
\hline 9 & $\% 84$ & 4.2 & أناقش أستاذة المساق فيما جاء من أفكار تصميمية ابداعية من خلال الثرح. & 17 \\
\hline 16 & $\% 76$ & 3.8 & أرى عدم ضرورة التواجد المباشر مع أستاذة المساق في تعلم مهار ات الابداع في تصميم & 18 \\
\hline 5 & $\% 90$ & 4.5 & أعتز بتصميماتي التي تمثل الانتاج التطبيقي للاراسة مساق تصميم الأزياء-2 زمن الحجر & 19 \\
\hline 1 & $\% 98$ & 4.9 & أؤمن بأن الحجر المنزلي لم بمثل عائقا في الوصول لمستوى ابداءعي منميز في دراسة & 20 \\
\hline
\end{tabular}

18

ـ في ضوء ما توصلت اليه الدراسة الحالية من نتائج ، يمكن عرض التوصيات التالية:

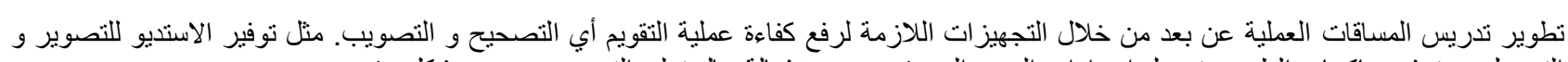

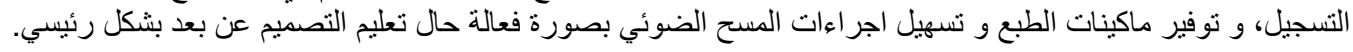

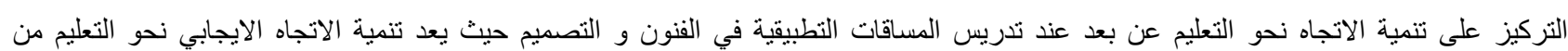
الأهداف الأساسية للمساقات التعليمية.

ضرورة اتخاذ الاجراءات اللازمة للاعتر اف بهذا النمط من التعليم داخل سلطنة عمان مع وضع معايير الاعتماد الأكاديمي المناسب.

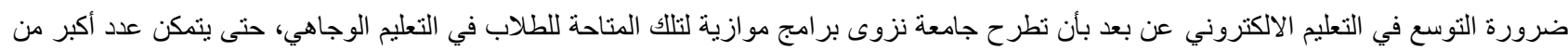

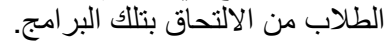
التوجه نحو الدراسات العلمية للتعليم بالو اقع الافتراضي Virtual Reality داخل الجامعات بسلطنة عمان و الدول العربية بوجه عام نظرا لأهميته في تدريس المساقات العملية.

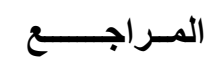

ـأبو زيد، أمل محمد محمود ـ عبيد، هند سعد محمد حسين:2020. "فاعلية التعلم النقال و التقويم البديل في تتمية بعض مهارات

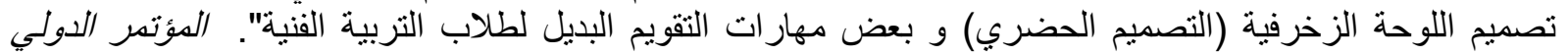
الثامن للجدعية العربية للحضارة و الثورة الصناعية الرابعة في ظل التعليم الالكتروني. الجمعية العربية للحضارة و ولية الفنون الاسلامية.

ـالبشري، يحيى بن جابر بن يحيى: 1996. "تنمية القدرات الابداعية ـ دراسة تجريبية على عينة من تلاميذ المرحلة المتوسطة". 
رسالة ماجستبر غبير منشورة. كلية التربية. جامعة الملك سعود.

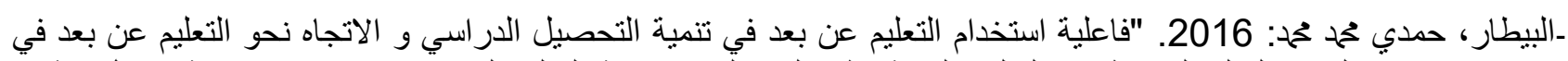
مقرر تكنولوجيا التعليم لاى طلاب الدبلوم العامة نظام العام الو احد شعبة التعليم الصناعي". دراسات عربية التربية في التربية و

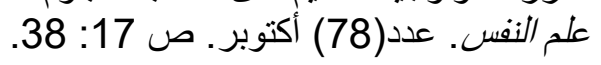

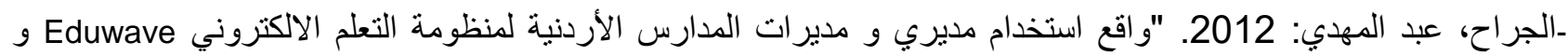

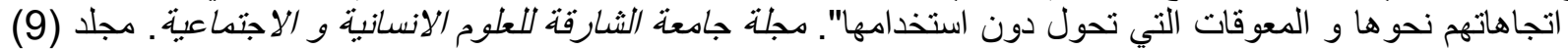

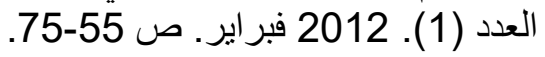

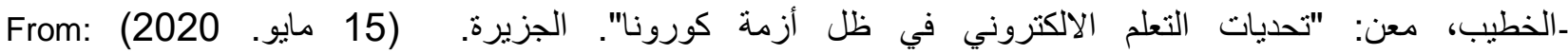
Aljazeera.net/opinion/2020/4/15

-الزدجالية، ميمونة: "تجربة التعليم الالكتروني في جامعات سلطنة عمان"، Schwlar World Wide. (19مايو. 2020) From: https://www.youtube.com/watch?v=ASUpKhEVfcg

ـ السيد، عبد الحليم محمود: "الابداع و الثخصية: دراسة سيكولوجية". دار المعارف. القاهرة. ط1. 1971.

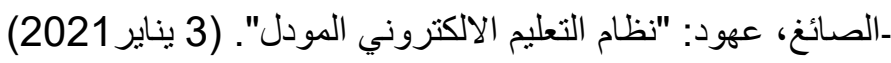

From: https://sites.google.com/site/ohoodalsaigh/home/nzam-altlym-mwwdlmoodel/rd-bwr-bwynt-Inzamalmwwdl/rd-Inzam-almwwdl-ppt

ـالطيطي، ححم حمد : 2007. "تنمية قدرات التفكير الابداعي". دار المسيرة للنشر و التوزيع و الطباعة. عمان. الأردن. ط3.

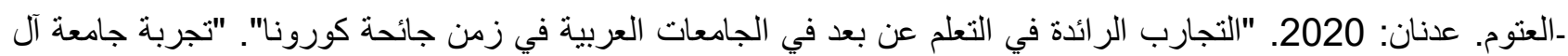

From: البيت". http://www.aaru.edu.jo/Lists/NewsandEvents/Disp_Form.aspx?ID=617

ـالعزام، ميسم فوزي مطير:2017. "ضمان الجودة النوعية في التعلم المفتوح و التعلم عن بعد". المجلة التربوية. مجلة كلبة

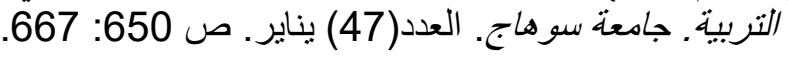

ـالغريب، زهر اء اسماعيل: 2009. "المقررات الالكترونية: تصميمها انتجهاـ نشرهاء تطبيقها تقويمها". عالم الكتب. القاهرة. ـالموسى، عبد الله ـ المبارك، أحمد: 2005. "التعليم الالكتورني الأسس و التطبيقات". مؤسسة شبكة البيانات. الرياض.

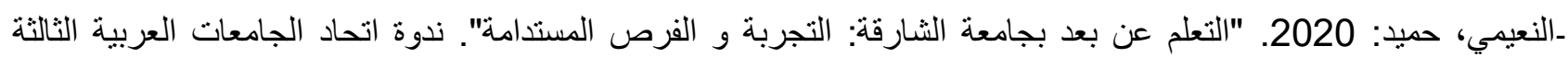

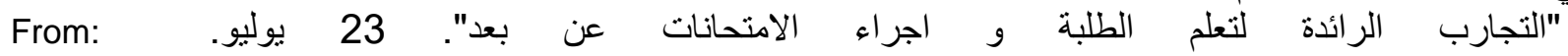
http://aaru.edu.jo/Lists/NewsandEvents/Disp_Form.aspx?ID=628

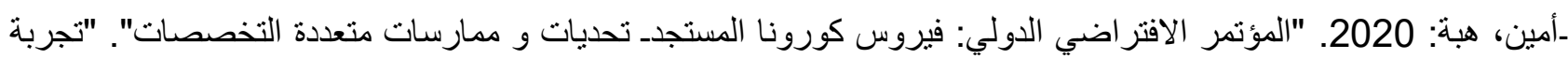
From: لية الطب البشري". http://www.helwan.edu.eg/english/?p=2119

-بسيوني، عبد الحميد:2007. "التعليم الالكتروني و التعليم الجوال". دار الكتب العلمية للنشر و التوزيع. القاهرة. -بهنسي، السيد : "ابتكار الأفكار الاعلانبة". عالم الكتاب. القاهرة. ط1.

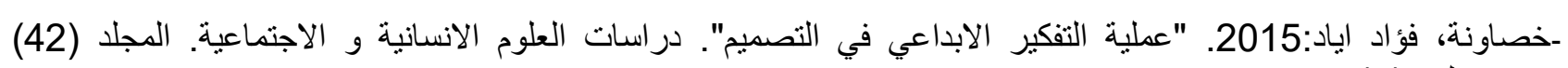

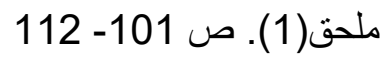

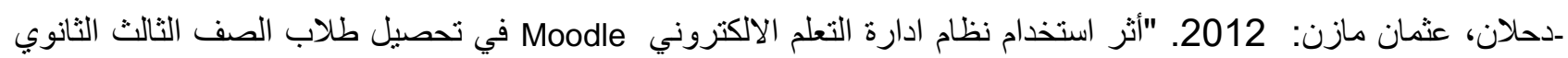

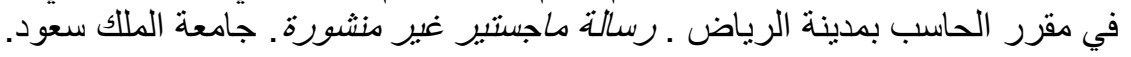

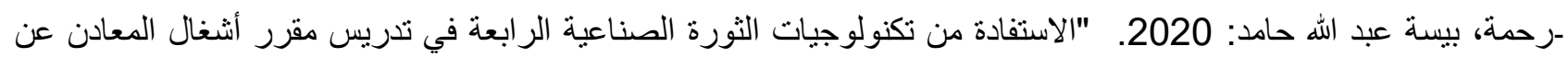
بعد". المؤتمر الدولي الثامن للجمعية العربية للحضارة و الثورة الصناعية الرابعة في ظل التعلية التيم الاكتكروني". الجمعية

العربية للحضارة و الفنون الاسلامية.

ـسافيدرا، خايمي:2020. "التعليم في زمن الكورونا: التحديات و الفرص". مدونات البنك الدولي. 30 مارس

From: https://blogs.worldbank.org/ar/education/educational-challenges-and-opportunities-covid-19-pandemic (8 August 2020) 
ـعاقل، فاخر:2008. "التربية و الابداع". دار العلم للملابين. بيروت. 1975.

ـ عبد الله، اياد حسين : "فن التصميم الفلسفة و النظرية و التطبيق- الجزء الأول". دائرة الثقافة و الاعلام. الثارقة. الامارات.

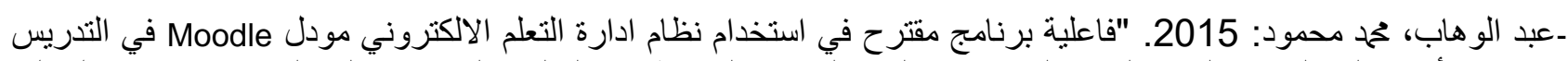

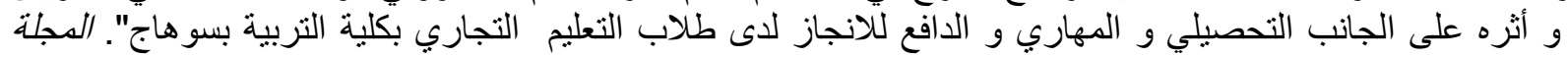

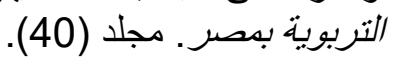

$$
\text { ـعزمي، نبيل جاد: 2008. "تكنولوجيا التعليم الالكتروني". دار الفكر العربي. مصر. }
$$

ـملكاوي، آمال رضا ـ مقدادي، ربى مححد ـ السقار، ماجدة مححد: 2015. "اتجاهات الطلبة نحو تعلم العلوم باستخدام التعلم

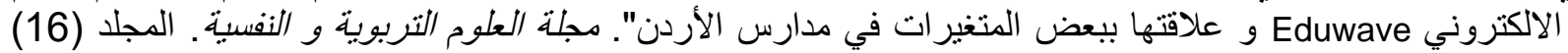

$$
\text { العدد (4) ديسمبر. ص ص 341: 369. }
$$

ـقطامي، يوسف. عرنكي، رغدة:2007. "نموذج مارازانو لتعليم التفكير للطلبة الجامعيين". ديبونو للطباعة و النشر و التوزيع. عمان. الأردن.

ـنجم، ماجد عبد السلام، شريف:2020 "التجارب الرائدة في التعلم عن بعد في الجامعات العربية في زمن جائحة كورونا".

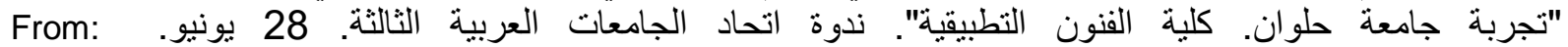
http://www.aaru.edu.jo/Lists/NewsandEvents/Disp_Form.aspx?ID=617

$$
\text { -نشو اني، عبد المجيد: 1985. " "علم النفس التربوي". دار الفرقان. عمان ـ الأردن. }
$$

Reid, N. (2007). "Thoughts on Attitude Measurement". Research in Science \& Technology Education. Vol. 24. No 1, pp 3:27.

Ronald, S. Brandt:( 2002). "On Creativity and thinking skills: A conversation with David Perkins". Education Leadership. May 1986. EBSCO Publishing. (4July 2020). From:

https://www.slideshare.net/alaseel56/on-creativity-and-thinking-skills-a-conversation-with-davidperkins

covid19: who.int/ar/emergencies/diseases/novel-coronavirus-2019/advice-for-public. (15 May2020)

Moodle: ar.wikipedia.org/wiki/Moodle. (23May 2020)

Dufault, Cynthia.: (2020)." Virtual Dance Instruction: Community Hubs". Arizona State University virtual conference. (14July, 2020). From: https://onlinexperiences.com/scripts/Server.nxp

World Health Organization. From: https://www.who.int/emergencies/diseases/novel-coronavirus2019/question-and-answers-hub/q-a-detail/coronavirus-disease-covid-19

$$
\begin{aligned}
& \text { الملاحق } \\
& \text { ملحق (1) } \\
& \text { استبانة اتجاه الطلاب بجامعة نزوى نحو التعليم الاكتثروني عن بعد } \\
& \text { مساق (تصميم الأزياء-2) زمن جائحة كورونا } \\
& \text { أعز ائي الطلاب، الرجاء استكمال استطلاع الرأي و ذلك لتبين مدى نجاح تجربة تدريس مساق تصميم الأزياء-2 فترة الحجر المنزلي أي النصف الثاني من كردئ } \\
& \text { فصل ألربيع 2019/ 2020. } \\
& \text { حيث أن نتائج الاستطلاع الذي قامت بتصميمه أستاذة المساق يقيم تجربة التدريس السابقة قبل الجائحة، ويساعد أيضا في التتبؤ لأي مشكلات خاصة }
\end{aligned}
$$

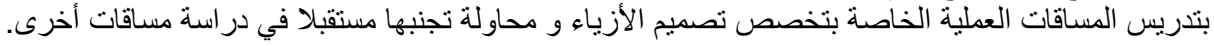

$$
\begin{aligned}
& \text { ملحوظة: كل العبار ات خاصة بمساق تصميم الأزياء-2 فقط الأباء } \\
& \text { يمكن وضع كلمة (نعم) عند المستوى المناسب لر أيك او ادر اج أب علامة. }
\end{aligned}
$$

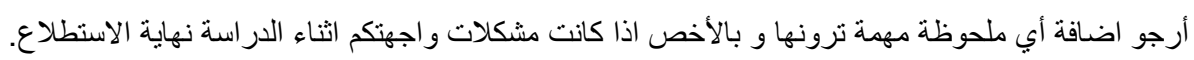

$$
\begin{aligned}
& \text { و لا مانع اذا تم اقتر اح بعض العبار ات التي ينم اضافتها لاستطلاع الرأي. } \\
& \text { (الثفافية تخدم العملية التعليمية بشكل ايجابي) }
\end{aligned}
$$


IJASOS- International E-Journal of Advances in Social Sciences, Vol. VII, Issue 19, April 2021

\begin{tabular}{|c|c|c|c|c|c|c|}
\hline 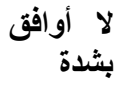 & لا أوافق & 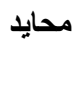 & 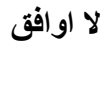 & 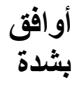 & العبارة & رقم \\
\hline & & & & & \multicolumn{2}{|c|}{ المحور الأول: الرغبة و الاستمتاع بتجربة التعليم } \\
\hline & & & & & 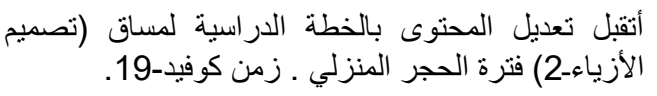 & 1 \\
\hline & & & & & عن التتع اجد بمرسم الجامعة. الحرية و الراحة للأداء العملي بالمنزل & 2 \\
\hline & & & & & أحساول انجاز التكليفات من واجبات و غيرها على أفضل & 3 \\
\hline & & & & & أشعر بالرضا عن أداء الأستاذة في تدريس المساق. & 4 \\
\hline & & & & & أخطائي في التصميم التطبيقي. عن الاسلوب الذي صوبت به الأستاذة & 5 \\
\hline & & & & & أشعر بالرضا عن تجربة الاختبار النهائي للمساق. & 6 \\
\hline & & & & & أحكم على نأنها ناجحة و مدتعة. دساق مساق (تصميم الأزياء-2) أثناء & 7 \\
\hline & & & & & أسلوب التعليم عن بعد. مساقات عملية جديدة مستقبلا من خلال & 8 \\
\hline & & & & & الثاني: تقدير قيمة و أهمية التعليم عن بعد في مجال & 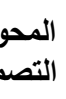 \\
\hline & & & & & أتفهم بوضوح الفصل الدراف المنشودة من دراسة المساق حتى & 9 \\
\hline & & & & & أتحمس لأداء الأنشطة التعليمية المطلوب انجاز ها. & 10 \\
\hline & & & & & على الثبكزة مهار اتي من خلال مشاهدة المزيد من مقاطع الفيديو & 11 \\
\hline & & & & & في الرسم بشغف التصميم. المزيد من المهارات التي ثرتقي بمستواي & 12 \\
\hline & & & & & 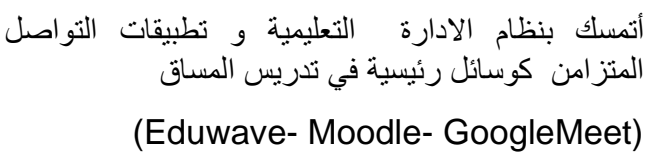 & 13 \\
\hline & & & & & 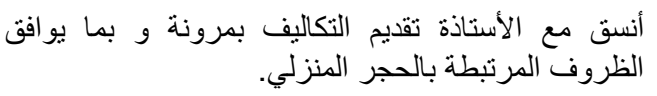 & 14 \\
\hline & & & & & أنعاون مع زملائي في تبادل المعلومات المبات حول الأنشطة و & 15 \\
\hline & & & & & أصوب التصناذة. التصميمات المقدمة للتقييم بناء على توجيهات & 16 \\
\hline & & & & & خلافل الثرحت الأستاذة فيما جاء من أفكار تصميمية ابداعية من & 17 \\
\hline
\end{tabular}




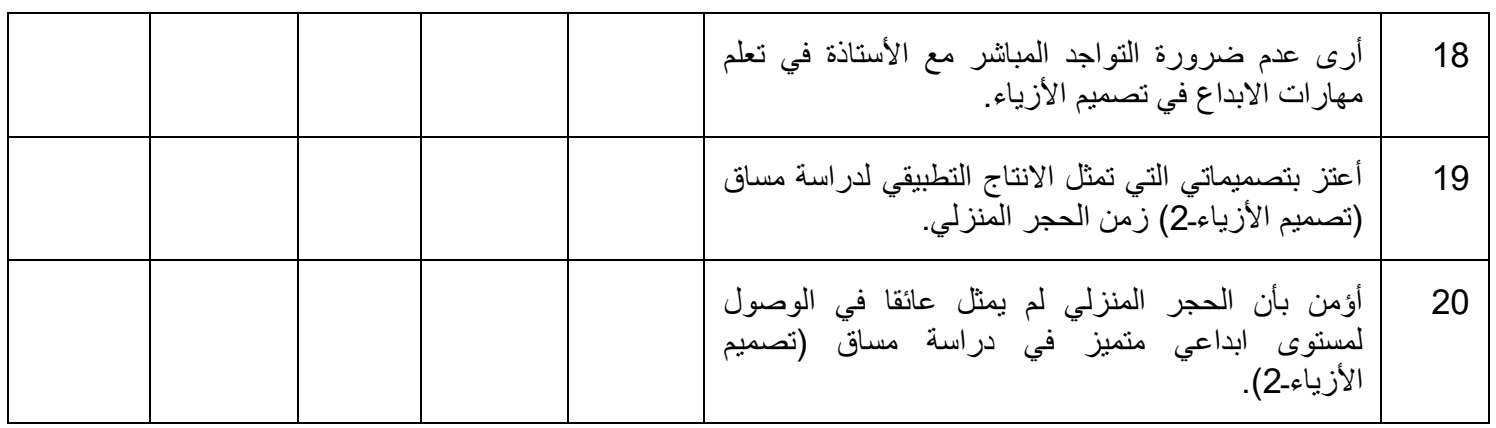

\section{ملحق رقم (2)}

الوحدات التعليمية الخمسة الخاصة بتتمية القدرات الابداعية في مساق (تصميم الأزياء-2)

بجامعة نزوى زمن جائحة كورونا

\begin{tabular}{|c|c|c|c|c|c|c|}
\hline التقويم و التقييم & الأنشطيمة & التعليمية & الموضوع/ المحتوى & الهُف & الابداعية & المحاضرة \\
\hline \multirow[t]{2}{*}{ 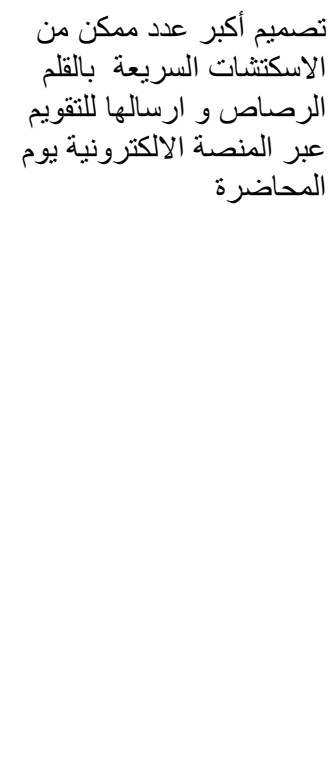 } & & & \multirow{2}{*}{ 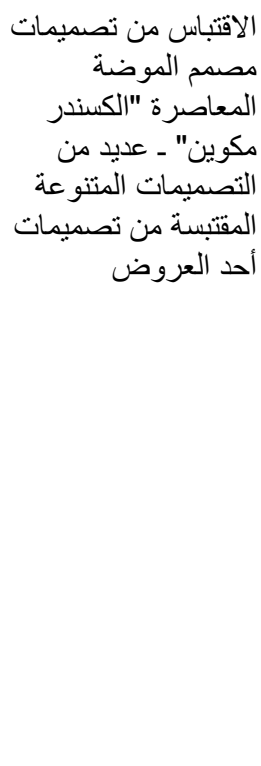 } & \multirow{2}{*}{ 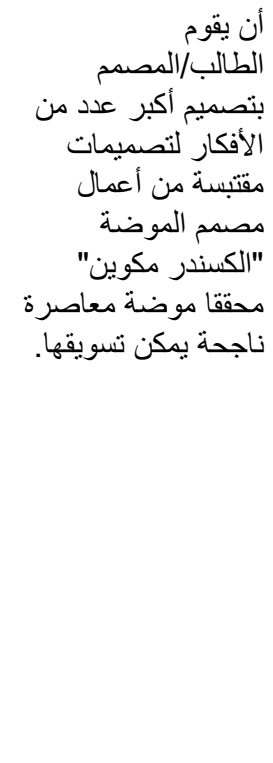 } & \multirow[t]{2}{*}{ الطلاقة } & \multirow[t]{2}{*}{ الأولى } \\
\hline & \multirow[t]{3}{*}{ تقديم ورقة } & \multirow[t]{3}{*}{ 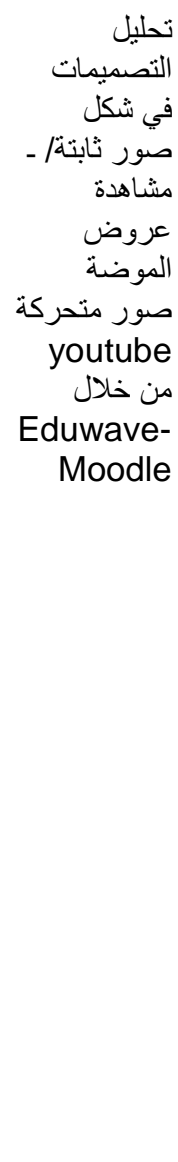 } & & & & \\
\hline 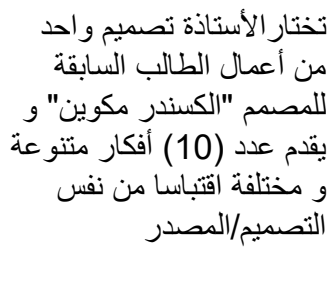 & & & 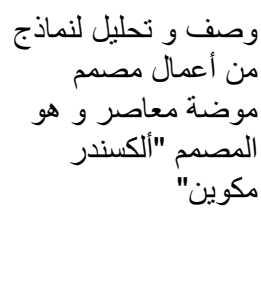 & 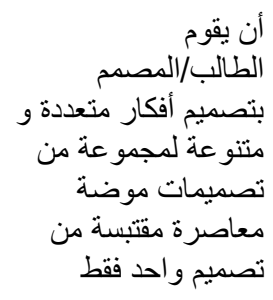 & المرونة & الثانية \\
\hline كل اضل (10) السابقة التفاصيل للتصميمات نفذها & & & 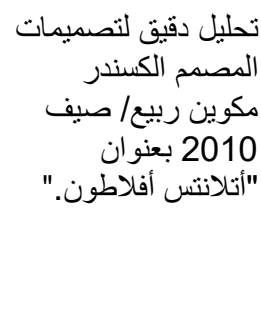 & 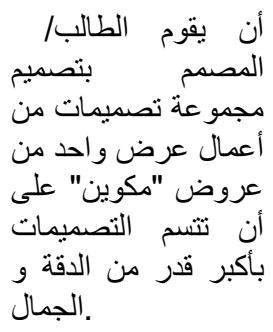 & التفاصيل & الثالثة \\
\hline
\end{tabular}


IJASOS- International E-Journal of Advances in Social Sciences, Vol. VII, Issue 19, April 2021

\begin{tabular}{|c|c|c|c|c|}
\hline تصكل تفيم (5) تصميها ثم تقويمهات مكتملة & & 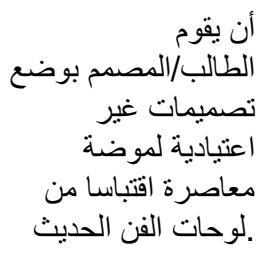 & الأصـالة & الر ابعة \\
\hline 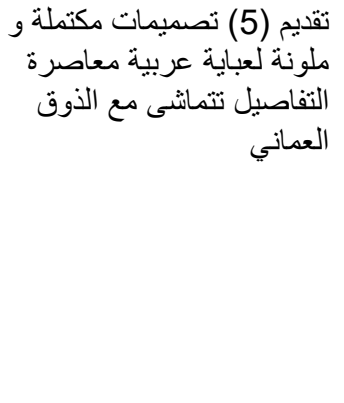 & 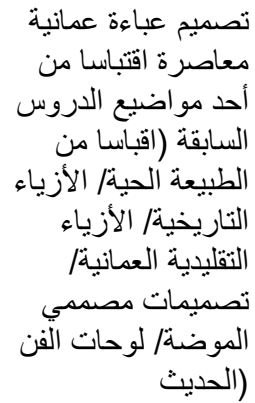 & 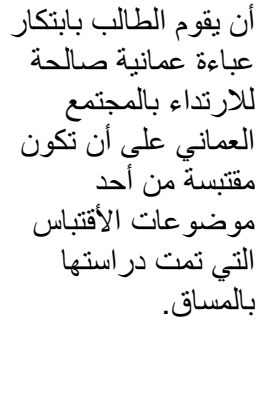 & للمشكلاتية & الخامسة \\
\hline
\end{tabular}

